Código JEL: F23, G12, K11, M20, M31

\title{
Nuevas dimensiones y problemáticas en el ámbito de la creación y gestión de marcas
}

\author{
Julio CERVIÑO \\ Universidad Carlos III de Madrid \\ jcervino@emp.uc3m.es \\ Verónica BAENA \\ Universidad Europea de Madrid \\ veronica.baena@uem.es
}

Recibido: 07-07-2014

Aceptado: 10-08-2014

\section{RESUMEN}

Este trabajo analiza la marca como factor de competitividad empresarial y fuente de ventaja competitiva sostenible. Desde una perspectiva integradora, y una vez esquematizo el estado de la investigación en materia de marcas, se analizan los aspectos más novedosos y actuales que presentan nuevos retos para la gestión de las marcas. En concreto, se interrelacionan las diversas áreas funcionales de la empresa para dar respuesta a la creciente problemática de las «marcas durmientes», la parametrización del concepto legal de «marca renombrada», las posibles situaciones de dilución de marca generadas por terceros, la interrelación entre valor de marca y competitividad internacional, y finalmente, la problemática de la valoración de las marcas y los efectos de la nueva norma ISO 10668 sobre valoración.

Palabras clave: Marcas durmientes, marca renombrada, dilución de marcas, internacionalización, valor de marca, ISO 10668. 


\title{
New dimensions and issues in the field of brand development and management
}

\begin{abstract}
This paper analyses the brand as a driver of business competitiveness and sustainable source of competitive advantage. From a holistic perspective, and after addressing the literature about branding, the newest and most current issues regarding brand management are discussed. Specifically, the different functional areas of the company are discussed to deal with the growing problem of «dormant brands», the parameterization of the legal concept of «brand awareness», the brand dilution generated by third parties, the relation between brand equity and international competitiveness, and finally, the issue of valuing brands as well as how the ISO 10668 may drive brand valuation.
\end{abstract}

Keywords: Dormant brand, brand awareness, brand dilution, internationalization, brand equity, ISO 10668.

Sumario: 1. Introducción; 2. La marca como activo estratégico; 3. Las marcas durmientes. 4. Marcas renombradas, su cuantificación y su posible dilución; 5. La internacionalización de la marca; 6. El valor financiero de las marcas: la nueva norma ISO 10668; 7. Consideraciones finales; Bibliografía.

\section{INTRODUCCIÓN}

La competitividad de la empresa puede estar ligada a su saber hacer sí aceptamos que una empresa es competitiva si es capaz de hacer productos y de prestar servicios con un binomio calidad-precio diferente al que define a sus competidores y es valorado positivamente por el mercado. Este saber hacer ha de ser especifico, diferenciado, y hace que el capital económico de la empresa se nutra por un conjunto de bienes intermedios que permiten producir nuevos bienes (productos y servicios). Este capital económico, bienes de activo de la empresa, puede ser de carácter físico y de naturaleza inmaterial o intangible. Este último se puede estructurar agrupar en tres grandes apartados: capital tecnológico (dota de capacidad para la producción física de los productos y de los servicios asociados), capital comercial (dota de capacidad para la comercialización, distribución y venta de los productos) y capital gerencial o directivo (dota de capacidad de gestión, coordinación y control de actividades). Puede decirse que, en mayor o menor medida toda empresa posee cierta dotación de cada uno de estas tres clases de capital económico, dependiendo la mayor proporción de uno u otro de la delimitación de su núcleo competitivo, estrictamente ligado a la fabricación y producción de bienes, a su comercialización y venta o preferentemente a la calidad y eficiencia gerencial o directiva. 
Los activos intangibles presentan un elevado nivel de especificidad y de conocimiento tácito lo que hace que el mercado como mecanismo de valoración y protección de dichos activos vea reducida su eficacia (Williamson, 1985). Estos activos presentan un elevado grado de ambigüedad causal ya que es difícil definir las relaciones de causalidad existente entre la actividad desarrollada y los resultados obtenidos (Lippman y Rumlets, 1982). Sin embargo, si se puede observar su incidencia en el desempeño y decisiones de la empresa.

En términos generales se puede decir que en una economía de servicios y del conocimiento el núcleo competitivo de las empresas y de los países son sus intangibles. En este sentido tiene virtualidad su protección tanto por parte de la empresa como del país a través de sus instituciones: organizaciones que registran los conocimientos codificables, leyes que las protegen y tribunales que velan por el cumplimiento de estas. En este contexto se sitúan la protección de los derechos de propiedad industrial e intelectual (patentes, marcas, nombres comerciales...).

La ventaja competitiva fundamentada en el capital comercial de la empresa se basa en el desarrollo de canales de distribución y venta y en la creación de marcas comerciales notorias. El capital comercial incluye know how sobre mercados, segmentos, procesos de distribución y venta (Sritavastava, et al., 2001; Glazer, 1991), y organización comercial. Sin embargo, en su génesis y desarrollo intervienen, en mayor o menor medida, otras áreas o funciones de la empresa. Por ello puede hablarse de la existencia de un fuerte imperativo por parte de las empresas para considerar que la responsabilidad de la gestión de la marca va más allá del departamento de marketing. En el proceso de creación y gestión de marcas deben participar muchas áreas organizativas de la empresa. Ciertamente, el área de marketing tendrá que liderar el proceso, pero sin lugar a dudas, el activo marca es demasiado importante para que toda la gestión y responsabilidad recaiga de manera exclusiva en el departamento de marketing. Es necesario que el área financiera comprenda el auténtico valor de la marca para entender que los recursos destinados a este activo son una inversión y no un gasto. En el área industrial y de servicios, uno de los principales vectores de creación de valor de marca es el capital humano, por lo que el departamento de recursos humanos debe estar alineado con los valores, identidad y personalidad que se intenta proyectar de la marca. Por último, y no menos importante, la inversión en marca, tanto desde la perspectiva de la innovación y el I+D (modelos de utilidad y patentes) como de los referentes visuales (trademarks, nombre de marca, logo, etc) tiene que ser protegida jurídicamente, por lo que la coordinación con el área jurídica es también primordial. En el siguiente gráfico 1 se presenta un modelo de interacción de las diversas áreas que deben ser coordinadas para una correcta gestión del activo marca.

Con esta visión integradora del activo marca, el objetivo de este trabajo es presentar y analizar los aspectos más novedosos, actuales y escasamente investigados que afectan a alguna de estas áreas de la empresa en su objetivo común de crear un 
valor de marca sostenible en el tiempo. En este sentido, este trabajo analizará, en una primera parte (apartado segundo) y brevemente el concepto marca y su consideración como activo estratégico y las principales áreas más desarrolladas en cuanto a la investigación académica. Este análisis nos permitirá establecer los aspectos ampliamente investigados, así como aquellos que, a nuestro entender, no han sido todavía estudiados o lo han sido de manera insuficiente a pesar de tener una máxima relevancia. Los aspectos analizados se relacionarán con las cuatro diferentes áreas de gestión del gráfico 1. Así, el tercer apartado analiza un aspecto de creciente actualidad, tal como es el incremento del "retro marketing" y su impacto en la recuperación y relanzamiento de las llamadas "marca durmientes". Este análisis nos llevará, en el apartado cuatro, a presentar y analizar la problemática de la cuantificación del concepto de marca renombrada, tipología establecida por la legislación española en materia de marcas en el año 2001 y que todavía, a fecha de hoy, no existe un consenso claro sobre su parametrización. Asimismo, en este apartado, y en relación al concepto del renombre de marca, se analiza también el concepto de dilución de la marca, un área de gran actualidad académica y profesional (principalmente en el ámbito legal) y en el que todavía la literatura especializada no ha podido ofrecer una solución adecuada. En el apartado cinco se plantea la marca como factor determinante de la realización de inversión directa en el exterior. A continuación, en el apartado seis se analizan el área de valoración económica financiera de la marca, la solvencia de los rankings publicados y la actual norma ISO 10668 sobre valoración económica de marcas. El trabajo finaliza a modo de resumen y conclusiones con unas consideraciones finales.

Gráfico 1

Visión Integral de la Importancia y Gestión de la Marca en la Empresa

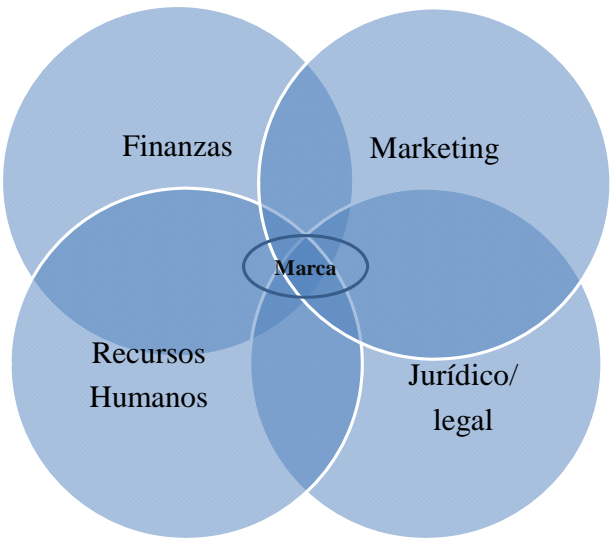


Con esta visión integradora del activo marca, el objetivo de este trabajo es presentar y analizar los aspectos más novedosos, actuales y escasamente investigados que afectan a alguna de estas áreas de la empresa en su objetivo común de crear un valor de marca sostenible en el tiempo. En este sentido, este trabajo analizará, en una primera parte (apartado segundo) y brevemente el concepto marca y su consideración como activo estratégico y las principales áreas más desarrolladas en cuanto a la investigación académica. Este análisis nos permitirá establecer los aspectos ampliamente investigados, así como aquellos que, a nuestro entender, no han sido todavía estudiados o lo han sido de manera insuficiente a pesar de tener una máxima relevancia. Los aspectos analizados se relacionarán con las cuatro diferentes áreas de gestión del gráfico 1. Así, el tercer apartado analiza un aspecto de creciente actualidad, tal como es el incremento del "retro marketing" y su impacto en la recuperación y relanzamiento de las llamadas "marca durmientes". Este análisis nos llevará, en el apartado cuatro, a presentar y analizar la problemática de la cuantificación del concepto de marca renombrada, tipología establecida por la legislación española en materia de marcas en el año 2001 y que todavía, a fecha de hoy, no existe un consenso claro sobre su parametrización. Asimismo, en este apartado, y en relación al concepto del renombre de marca, se analiza también el concepto de dilución de la marca, un área de gran actualidad académica y profesional (principalmente en el ámbito legal) y en el que todavía la literatura especializada no ha podido ofrecer una solución adecuada. En el apartado cinco se plantea la marca como factor determinante de la realización de inversión directa en el exterior. A continuación, en el apartado seis se analizan el área de valoración económica financiera de la marca, la solvencia de los rankings publicados y la actual norma ISO 10668 sobre valoración económica de marcas. El trabajo finaliza a modo de resumen y conclusiones con unas consideraciones finales.

\section{LA MARCA COMO ACTIVO ESTRATÉGICO}

En la economía moderna, tanto real como virtual, las marcas se han convertido en activos críticos para la creación de valor en las empresas. Pero su valor no es solo comercial, sino también profundamente simbólico, siendo unos claros exponentes del desarrollo material, tecnológico y social de un país, lo que las convierte en excelentes embajadores de la imagen nacional en los mercados exteriores (Cerviño y Rivera, 2007).

La marca es un elemento distintivo de los productos y servicios a los que están asociadas y por lo tanto de su calidad y atributos (cualidades como diseño e imagen, por ejemplo). La marca es además un elemento diferenciador de la empresa y también, en ocasiones, de su país de origen al contribuir positivamente a su imagen. La marca constituye uno de los núcleos determinantes del capital 
comercial de la empresa y como elemento codificable y registrable es susceptible de protección institucional y de ser objeto de comercio. Consecuentemente puede ser valorada de forma individualizada e independiente de otros activos intangibles. La reputación de una marca no solo se circunscribe a su sector de actividad sino que puede transcender este y ganar renombre para el público en general; aspecto este que también ha sido objeto de regulación para evitar que su uso asociándose a otros fines (productos o servicios) distintos los propios de origen puede constituir una pérdida de valor indirecto para la empresa titular de dicha marca.

Las marcas reputadas facilitan la decisión de compra y pueden constituir verdaderas palancas para la fidelización a largo plazo de los consumidores. Además identifica a la empresa y es un componente crucial de su imagen y reputación, afectando a la relación con los grupos interesados internos (empleados, directivos, accionistas).

El consumidor puede incurrir en costes de selección de los productos a adquirir, especialmente cuando no hay experiencia previa en el consumo de dicho bien para confirmar su calidad (Aaker, 1996; Keller, 1998). De hecho el mercado tiende a confiar en las empresas que poseen marcas reputadas y considera que los productos de estas empresas son de mejor calidad y garantía (Hill y Kim, 1990). Desde el punto de vista del consumidor, la marca simplifica la selección de los productos y por tanto, de la decisión de compra (Sashi y Karuppur, 2002).

La creación y gestión de marcas ha sido uno de los temas de máxima prioridad de la alta dirección en esta última década, debido a la creciente constatación de que las marcas son uno de los activos que más valor presentan para las empresas (Kelller y Lehmann, 2006). Además, en el actual proceso de globalización empresarial, la marca aparece como una variable estratégica de creciente importancia dentro de las decisiones, políticas y estrategias de internacionalización de la empresa (Kelz y Block, 1993; Luostarianen y Gabrielsson, 2004). Es un hecho cada vez más indiscutible que la competitividad de las empresas se sitúa en el campo de los intangibles, y dentro de éstos, la marca resulta determinante (Durán, 2002; Cerviño, 2002).

Tradicionalmente, en las empresas de bienes de consumo la estrategia gira alrededor de tres pilares fundamentales: la marca, el marketing y los clientes. Sin embargo, hasta fechas recientes, la gestión de marca no estaba tan generalizada en empresas de servicios, tecnología o industriales. A menudo era considerada como un coste extra más que como un vector estratégico del negocio, pudiendo pasar a ser uno de los elementos en los que no invertir. En consecuencia, la mayor parte de la investigación en el área de marcas se ha centrado en los mercados de consumo, y principalmente en los denominados PCAR -Productos de Consumo de Alta Rotación - FMCG en terminología inglesa (Leek y Christodoulides, 2011; Baumgarth, 2010). 
La investigación en el área de servicios es más limitada y en el área industrial ciertamente escasa (Lynch y de Chernatony, 2007; Ohnemus, 2009). Sin embargo, esta situación está cambiando y la gestión de la marca se ha revelado también prioritaria para todo tipo de sectores o industrias, comenzando hace ya varios años en el área de servicios y más recientemente en el área industrial. Por un lado, en el nuevo entorno económico, el peso del sector servicios está en continuo crecimiento dentro del conjunto de la economía global, lo que ha generado un creciente desarrollo de marcas de servicios (Iglesias, Singh y Casabayó, 2011). Por otro, en el sector de los bienes industriales (el llamado Business to Business) se tenía la creencia, tanto en el ámbito académico como el profesional, de que los clientes industriales no se veían afectados por los valores y beneficios emocionales ligados a las marcas. Muchos de los cambios acaecidos en el entorno económico actual, tales como una relativa y creciente homogeneidad en la calidad de los productos, los procesos de outsourcing y deslocalización productiva y el número decreciente de contactos y relaciones personales debido al incremento exponencial de las comunicaciones electrónicas, han incrementado el interés en la gestión de la marca industrial (Baumgarth, 2010).

Además, en un contexto donde la importancia de la marca traspasa ya todos los sectores e industrias, la marca corporativa adquiere una especial relevancia. Mientras que el objetivo último de la marca de producto es la fidelización y satisfacción del consumidor (con un creciente interés también en las relaciones con los proveedores); las marcas corporativas tienen una visión mucho más amplia, que tiene en cuenta los intereses de muchos stakeholders (Balmer y Gray, 2003; Anisimova y Movando, 2010), no solamente los consumidores y/o clientes, pero también los empleados, proveedores, inversores, instituciones y los medios de comunicación. Esta visión más global, en la que la organización es la marca, está ganando importancia en un mundo cada vez más conectado, transparente y globalizado. Hay todavía mucha confusión al respecto, y en ocasiones los términos de marcas de servicios y marcas corporativas se utilizan como sinónimos (de Chernatony et al., 2006). Lo mismo ocurre con las marcas industriales, donde la estrategia de marca corporativa domina el sector industrial. Sin embargo, no todas las marcas de servicios o industriales son necesariamente marcas corporativas.

Desde la perspectiva empresarial y enmarcada en un mundo globalizado, con una fuerte competencia externa vía precios, solo es posible ganar cuotas de mercado o mantener una sólida posición competitiva incorporando una estrategia decidida de diferenciación y marca. Tener un buen producto u ofrecer un buen servicio es condición necesaria pero no suficiente para tener éxito en el mercado. Es preciso diferenciarse de la competencia incorporando a los atributos físicos valores emocionales que concedan a la empresa una ventaja sensible y sostenible respecto a los competidores. La marca permite identificar y proyectar los valores de la empresa o la institución, sus productos o servicios, los diferencia de los de la competencia, refleja cómo se organiza y, bien gestionada, desencadena una conexión emocional y 
de confianza con los clientes, generando lealtad y fidelidad con su público objetivo, y por lo tanto, flujos de caja sostenibles en el tiempo. En un entorno dominado por el poder de la imagen, las empresas y productos no asociados a iconos visuales emocionalmente reconocibles no existen. Finalmente, y dada su relevancia como generador de flujos de caja sostenibles en el tiempo, las marcas no son solo unos activos comerciales en propiedad de la empresa, sino que también lo son en términos estrictamente financieros (Keller y Lehmann, 2006), y como hemos señalado anteriormente constituyen un componente esencial del capital comercial de la empresa.

\subsection{La Marca como fuente de ventaja competitiva: un análisis de la literatura relevante}

Las marcas manifiestan su importancia en tres niveles fundamentales: en el mercado de clientes/consumidores, en el mercado de productos/servicios, y en el mercado financiero. Dada la importancia de las marcas en una economía muy competitiva y globalizada (Steenkamp, Batra y Alden, 2003), la investigación académica sobre las marcas es ciertamente extensa - principalmente en productos de consumo -, cubriendo un amplio abanico de temas y con investigaciones empíricas que, en conjunto, han contribuido a avanzar en la comprensión del fenómeno marcario.

En un extenso estudio sobre los principales trabajos y áreas de investigación más relevantes en materia de marcas (ver Keller y Lehmann, 2006) se establecen cinco grandes áreas íntimamente relacionadas con las decisiones estratégicas y operativas que frecuentemente tienen que tomar las empresas y sus directivos. Estas cinco áreas son: 1) Establecimiento y desarrollo del posicionamiento de la marca; 2) Integración de las decisiones de marketing con las decisiones de marca con objeto de generar un mayor valor de marca; 3) Valoración y métrica del rendimiento de las marcas; 4) Estrategias de crecimiento a partir del apalancamiento en marcas y; 5) Gestión estratégica de la marca.

Las decisiones sobre el posicionamiento de la marca condicionan las actividades y los programas de marketing. Desde una perspectiva estratégica, el posicionamiento trata de establecer asociaciones relevantes de la marca en la mente de los consumidores y otros "stakeholders" con objeto de diferenciar la marca y establecer una superioridad estratégica (Keller, 2002). Además de la selección de los atributos tangibles del producto, las áreas más importantes para un posicionamiento competitivo y ampliamente analizadas en la literatura se centran en señalar los principales atributos intangibles para el posicionamiento de marcas: análisis de la personalidad de la marca (la marca como persona), relaciones entre la marca y sus públicos objetivos (lealtad, fidelidad, compromiso...), marketing de experiencias y su aplicación al posicionamiento de la marca e imagen y reputación corporativa y su relación con el valor de las marcas. 
La segunda gran línea de investigación trata de establecer el correcto alineamiento entre las estrategias y actividades generales de marketing con las decisiones de marca, con objeto de crear sinergias y en última instancia generar un mayor valor de marca. Dentro de este área los aspectos más relevantes se centran en cuáles son los elementos de la marca que generan más valor de marca, el impacto de las estrategias coordinadas de comunicación y distribución, y la interacción entre las variables corporativas de control y los eventos externos fuera del control empresarial.

La tercera gran área de la investigación en materia de marcas se ha centrado en la valoración y la cuantificación del rendimiento de las marcas y el cálculo de su valor: valor para los consumidores y valor económico-financiero. Ciertamente, para gestionar adecuadamente la marca se necesita conocer, medir y gestionar su valor. Dos sub-áreas han centrado el interés de la investigación en esta área: la medición y valoración del capital (valor) de marca a diferentes niveles - consumidores, mercado y económico-financiero; y la relación del valor del consumidor con el valor de marca.

Otra línea de investigación se ha centrado en las estrategias de crecimiento a partir del apalancamiento en marcas. Las marcas son plataformas que permiten establecer estrategias de crecimiento corporativo, tanto a nivel doméstico como en los mercados internacionales. Las marcas con valor de mercado permiten un crecimiento sostenido a través de la extensión de líneas de productos o extensión de la marca a otras categorías. Sin embargo, un fracaso en la extensión de la marca puede provocar efectos muy negativos, generando lo que se define como dilución de marca. Por lo tanto, las sub áreas más investigadas a este respecto son las extensiones de marca y la dilución de marca. Ciertamente, también cabe el análisis de las marcas como palancas para desarrollar estrategias de internacionalización, si bien, esta área la analizaremos en el siguiente apartado.

Por último, otra rama de la investigación académica se centra en la gestión estratégica de la marca, incluyendo la adecuación y gestión de la cartera de marcas, los efectos de las estrategias de co-branding y alianzas de marcas y la gestión internacional y aspectos interculturales (cros-cultural) de la marca, incluyendo en este último caso los efectos del "Made in" o "país de origen" de la marca en la competitividad de los productos. En el anexo 1 se recogen estas cinco grandes líneas de investigación en el área de marcas; con una breve explicación de sus apartados y los trabajos más relevantes.

\section{2. Áreas de creciente interés en la investigación de marcas}

La investigación realizada en el ámbito académico sobre las marcas ha cubierto una extensa problemática con objeto de conseguir una mejor y mayor comprensión de este activo intangible de alto contenido estratégico en la generación de valor empresarial. En el Anexo I se proyectan los aspectos ampliamente investigados por autores relevantes en el área. Ahora bien, también es cierto que los cambios del mercado actual, tan dinámico y cambiante, presentan nuevos retos a la gestión y 
análisis de las marcas. Retos que se escapan de la propia responsabilidad de un departamento de marketing, y tal como señalamos anteriormente, tienen que ser gestionados desde una perspectiva global de la organización.

Dentro de esta perspectiva, en los siguientes apartados analizaremos aspectos nuevos que apenas han sido tratados o investigados en la literatura especializada y que a nuestro entender serán relevantes para una correcta comprensión y gestión del fenómeno marcario.

\section{LAS MARCAS DURMIENTES}

Cuando existen marcas inactivas (fuera del mercado) y que en el pasado fueron renombradas o muy notorias pueden ser calificadas de "durmientes” y si se considera que debido a su pasada reputación tienen además un valor de notoriedad residual pueden ser fácilmente activadas de nuevo y con una inversión posiblemente muy inferior a la que habría que incurrir para crear una nueva marca y hacerla reputada. Es decir, son marcas que mantienen en el imaginario colectivo una cierta notoriedad, imagen y asociaciones de marca, fruto de haber disfrutado de una gran notoriedad en el pasado ${ }^{1}$.

Una marca "durmiente" no tiene valor per se, al estar fuera del intercambio comercial de bienes y servicios. Su valor económico y comercial hay que considerarlo en el contexto de un "relanzamiento" o "reactivación" en el mercado, sea en su categoría original o en otra diferente, dado que las marcas que han alcanzado valores elevados de notoriedad a lo largo de sucesivos años suelen disfrutar de una notoriedad extremadamente persistente (Aaker, 1994). La reactivación de marcas durmientes puede ser una estrategia adecuada en ciertos sectores caracterizados por una saturación de marcas y excesiva rivalidad competitiva, y siempre y cuando la marca conserve un "valor residual" importante y unas asociaciones positivas (Bellman, 2005). Su valor (goodwill) residual (valor capital comercial inactivo) determinará la cuantía y naturaleza de la inversión de reactivación, fundamentalmente en marketing y comunicación.

Señalar que en estos últimos años ha habido una tendencia a "resucitar" y "recuperar" marcas y productos que estaban fuera del mercado desde hace años (Bellman, 2005; Brown, Kozinets, y Sherry, 2003). Esta tendencia es muy clara en el sector del automóvil, con el relanzamiento del Mini, el "Escarabajo de Volkswagen” o

\footnotetext{
${ }^{1}$ La literatura utiliza diversas acepciones en relación a estas marcas, unas más utilizadas en el área de marketing, tales como marcas durmientes del inglés "dormant brands"; marcas huérfanas - "orphan brands", o también marcas "fantasma”, del inglés "ghost brands" (ver Carbonara, 2009). En el ámbito jurídico se utilizan acepciones tales como marcas discontinuadas (discontinued brands); o marcas Zombie (ver Gilson y Gilson-LaLonde, 2008).
} 
más recientemente, el "600” de Fiat. Es una tendencia de "retromarketing” que busca el efecto nostalgia en ciertos segmentos del mercado así como un efecto intertemporal o de transmisión intergeneracional (Brown et al. 2003). Algunas de las reactivaciones más famosas de marcas de estos años han sido, entre otras: Commodore, Indian Motorcycle, Tab, Hydrox Cookies y Café Brim. En España tenemos también casos notorios como la "resurrección" con éxito de la emblemática cerveza catalana Moritz en 2005, que estaba fuera del mercado desde 1978. Más recientemente, en 2009, Pepsico España decidió relanzar la marca Matutano en ciertas categorías de productos, que desde hacía diez años había sido sustituía por su marca global Lays.

En general, estas reactivaciones se realizan por los propietarios originales de las marcas o bien por terceras empresas que compran los derechos de la marca, bien vía adquisición o licencia, al propietario original. Si la activación se realiza directamente por o con el consentimiento del anterior propietario de la marca, nos encontramos ante una decisión puramente comercial y estratégica donde no tiene por qué existir ningún conflicto legal con terceros. Ahora bien, si la activación de una marca "durmiente" se realiza por un tercero, sin autorización ni consentimiento de su anterior titular, podemos estar ante un caso de apropiación de un "valor residual" importante a coste cero - lo que puede ser calificado como "free riding" - pero más importante todavía, ante una situación que puede generar problemas importantes de dilución de marca al anterior titular, siempre y cuando la "marca durmiente" siga vinculándose y/o asociándose al anterior propietario y a sus marcas.

Una posible actuación de terceros puede ser facilitada por las correspondientes legislaciones. En este sentido podemos hacer referencia al artículo 39, capítulo II de la actual Ley española de Marcas (Ley 17/2001 de 7 de Diciembre) que sobre la obligación de uso de la marca señala que:

"Si en el plazo de cinco años contados desde la fecha de publicación de su concesión, la marca no hubiera sido objeto de un uso efectivo y real en España para los productos o servicios para los cuales esté registrada, o si tal uso hubiera sido suspendido durante un plazo ininterrumpido de cinco años, la marca quedará sometida a las sanciones previstas en la presente Ley, a menos que existan causas justificativas de la falta de uso". Y en el artículo 55 - apartado c - de esta Ley se indica que se declarará la caducidad de la marca y se procederá a cancelar el registro, y entre otras situaciones, "Cuando no hubiera sido usada conforme al artículo 39 de esta Ley”. En esta misma línea se posicionan la gran mayoría de legislaciones internacionales en materia de marcas, incluido el Reglamento europeo sobre la Marca Comunitaria².

Por lo tanto, puede darse el caso que un titular original de una "marca durmiente" se enfrente a una situación en la que un tercero - incluso, un competidor - la utilice

\footnotetext{
2 Reglamento (CE) n 40/94 del Consejo, de 20 de diciembre de 1993, sobre la marca comunitaria.
} 
alegando que la marca ha caducado por falta de uso. Un caso reciente en España es el intento de utilización de la marca de hipermercados Continente en el mercado español por el grupo portugués de distribución Sonae, alegando que Carrefour ha perdido la marca por caducidad, dado que desde 2001, año de la fusión de Pryca y Continente bajo la marca corporativa Carrefour, la marca Continente no ha sido utilizada en el mercado español.

Una marca notoria puede desaparecer del mercado por diversos motivos (tecnológicos, competitivos, institucionales). En los últimos años, los principales motivos de desaparición de muchas marcas notorias y renombradas es la racionalización de las carteras de marcas y la implementación de estrategias de desarrollo e implementación de marcas globales (Cerviño, 2002). Con objeto de alcanzar una mejor eficacia financiera y operativa, así como la búsqueda y consolidación de una imagen global, se aprecia una tendencia creciente a la consolidación y racionalización internacional de las carteras de marcas por parte de las empresas multinacionales, buscando crear grandes marcas globales y limitando la utilización de marcas locales. Estos procesos comenzaron a mediados de los noventa por empresas como Procter \& Gamble, Philip Morris, Nestlé o Unilerver ${ }^{3}$. Conjuntamente a este proceso, se limitó el lanzamiento masivo de nuevas marcas, se unificaron las marcas globales con las locales y se vendieron las que, a pesar de tener una clientela fiel, tuviesen un mercado reducido. Por ejemplo, recientemente Unilever vendió su marca Nocilla al grupo Nutrexpa. A pesar de ser una marca líder local, no tenía presencia global y su dimensión frente a Nutella, la líder global, era insignificante. Estos procesos de racionalización de marcas a nivel global siguen vigentes todavía y en todos los ámbitos, tanto de consumo, servicios como industriales. En España, hace tan solo pocos años que Nestlé retiró su marca emblemática de helados "Camy" para implantar su marca corporativa en toda la división de helados a nivel global. Ciertamente, estos procesos de racionalización hacen que muchas marcas de ámbito local o regional pasarán a ser parte del creciente grupo de "marcas durmientes" en el mundo.

Los procesos de adquisiciones y fusiones empresariales, y la implantación posterior de marcas globales será la principal estrategia a seguir. La rivalidad competitiva de un gran número de sectores obliga a las empresas a desarrollar estrategias de crecimiento vía adquisición y fusión de empresas, lo que conlleva la adquisición de marcas diversas en los distintos mercados, que disponen de notoriedad local importante y de una amplia base de clientes y cuota de mercado. Ahora bien, la mayor globalización de los mercados, la creciente movilidad internacional de los consumidores, así como la paulatina internacionalización de competidores, proveedores y distribuidores, favorecen en mayor medida el desarrollo de estrategias de marcas globales frente a las de marcas locales. Dado que la ventaja competitiva

\footnotetext{
${ }^{3}$ Ver "Procter \& Gamble Hits Back", Business Week, 19 de julio de 1993, pp. 228-33.
} 
global se sustenta en los recursos intangibles y capacidades que puedan ser transferidos y acumulados globalmente (Itami y Roehl, 1987), la empresa debe entonces crear y desarrollar marcas que sean fácilmente transferibles a la esfera internacional. Es decir, marcas con una orientación global que minimicen las barreras competitivas, culturales y legales de los diversos entornos internacionales. En este sentido, la estrategia de creación de marcas globales o internacionales tiene un mayor peso estratégico que la creación y/o mantenimiento de marcas locales para los respectivos mercados (Steenkamp, Batra y Alden, 2003; Gelder, 2005; Townsend, Yeniyurt y Talay, 2009).

La respuesta estratégica de la empresa compradora suele centrarse en transferir la marca local comprada (con sus clientes y cuota de mercado) a la identidad de marca global que se quiere implantar. Esta estrategia se define como "migración de marca". Estos procesos se dan tanto en el área de productos de consumo como industriales o de servicios. Las marcas españolas han sido muy activas en este tipo de procesos en estos últimos años. Un caso reciente es la implantación global de la marca Banco Santander en todos sus mercados, en a reciente implantación de la marca Banco de Santander en el Reino Unido a través de la marca local Abbey. En estos casos, tanto la marca "El Águila” en España como “Abbey National” en el Reino Unido pasarán a la senda de creación de "Marcas Durmientes" en un futuro.

En el siguiente gráfico 2 presentamos un esquema de las tres fuentes de generación de marcas "durmientes". En general, las marcas se "abandonan" o se dejan “durmientes”, además de por motivos de fracaso empresarial, fundamentalmente por imperativos estratégicos centrados en la creación de grandes marcas globales, líderes en sus respectivos mercados.

Gráfico 2

Fuente de creación de "Marcas Durmiente"

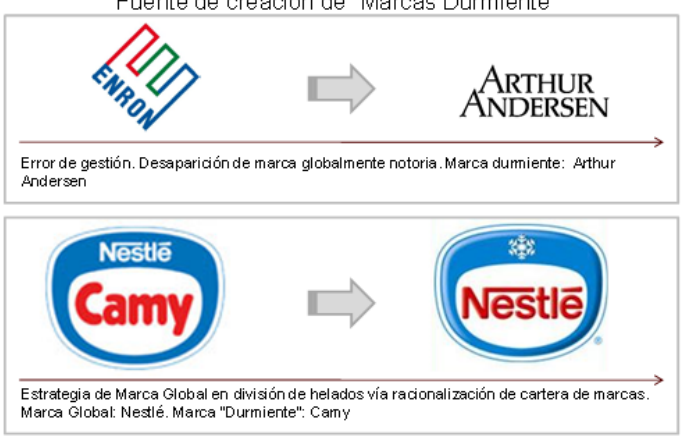


Sin embargo, y a pesar de no ser utilizadas en el tráfico mercantil, estas marcas “durmientes” mantienen un importante valor residual en el mercado, derivado del mantenimiento de una fuerte notoriedad así como de su vinculación con su categoría y asociación con su marca matriz. Las marcas que han sido notorias o renombradas, mantienen durante años su notoriedad y reconocimiento en el mercado (Aaker, 1996; Sutherland y Sylvester, 2000). Este periodo de notoriedad residual va mucho más allá de los cinco años que delimitan la mayor parte de las legislaciones en materia de marcas para la caducidad de las mismas, sobre todo si han sido pioneras en sus respectivas categorías (Lilien y Yoon, 1990; Karder y Gurmurthy, 1992; Robinson, 1998). La novedad de la categoría y la marca genera una gran atención por parte del público y una gran parte de ésta será memorizada por un largo periodo de tiempo (definido como "long-term memory" por Anderson, 1983).

Por lo tanto, entendemos que tanto la legislación española como europea, entre otras, no están adaptadas a la fuerza que representan las marcas notorias y renombradas en la actualidad, al ser estas las receptoras fundamentales de las multimillonarias inversiones en comunicación e imagen de una economía ampliamente mediatizada. En este contexto, las legislaciones deberían adaptarse y ampliar de manera significativa el periodo temporal de caducidad de las marcas notorias y renombradas por falta de uso efectivo en el tráfico mercantil, dado que son éstas las que mantienen en el tiempo su fuerza en el imaginario colectivo.

\section{MARCAS RENOMBRADAS, SU CUANTIFICACIÓN Y SU POSIBLE DILUCIÓN}

La consideración de marcas famosas o renombradas y sus potenciales problemas de dilución de marca han sido considerados por instituciones multilaterales con competencia en la materia como la Organización Mundial de la Propiedad Industrial (OMPI), la OMC (Organización de Mundial del Comercio) y la Comisión Europea. Conceptos que también han sido incorporados en los principales mercados industrializados (EE.UU., Unión Europea y Japón). Sin embargo a pesar de su relevancia son escasos los trabajos publicados hasta la fecha en esta materia (Morrin, Lee y Allenby, 2006; Simon, 2006).

Las leyes en derecho y protección de marcas (nombres de marca, logotipos, slogans, formas tridimensionales, gráficos, colores y otros símbolos) se centran principalmente en conferir al titular de la marca legalmente registrada un derecho exclusivo de uso. El titular la marca estará facultado para prohibir a cualquier tercero el uso, sin su consentimiento, en el tráfico económico, de a) cualquier signo idéntico a la marca para productos o servicios idénticos a aquellos para los que la marca esté registrada; y b) de cualquier signo que, por ser idéntico o similar a la marca y por ser 
idénticos o similares los productos o servicios designados por la marca y el signo, implique por parte del público un riesgo de confusión, que comprende el riesgo de asociación entre el signo y la marca ${ }^{4}$.

También puede existir la situación en la que los consumidores, detallistas o distribuidores se enfrentan a productos o servicios de diferentes compañías que utilizan la misma o parecida marca, sin estar en ningún caso confundidos respecto a su origen, titularidad o asociación, pero la marca notoria o renombrada puede verse perjudicada por tal coexistencia de nombres de marca idénticos o parecidos. Por ejemplo, una compañía de estética corporal que comience a publicitar sus servicios como "Estética Corporal Zara" y que los consumidores entiendan que esta empresa no tenga conexión alguna con la cadena de moda del mismo nombre - es decir, no hay asociación ni confusión - la empresa titular de la marca renombrada no podría ejercer ningún tipo de acción legal contra dicha empresa en defensa de la distintividad y valor de su marca en el mercado, a no ser que la cadena Zara tuviese también registrada su marca en esa misma clasificación de servicios.

Para hacer frente a este tipo de problemas y derivados hay que dar respuesta a dos preguntas fundamentales: ¿Qué es una Marca Renombrada? ${ }^{5}$ y ¿Cómo cuantificar el renombre de marca? La actual ley española de marcas considera marca notoria la que, por su volumen de ventas, duración, intensidad o alcance geográfico de su uso, valoración o prestigio alcanzado en el mercado o por cualquier otra causa, sea generalmente conocida por el sector pertinente del público al que se destinan los productos, servicios o actividades que distinguen dicha marca o nombre comercial.

La marca renombrada tiene todavía más fuerza y valor que la marca notoria, ya que es aquella no sólo conocida por el público objetivo (sector pertinente) de la marca, sino por el público en general, y goza en este caso de una mayor protección jurídica. La ley española de marcas es ciertamente novedosa y pionera en este ámbito, ofreciendo una protección especial y específica a las marcas consideradas como renombradas, otorgándoles una protección jurídica más allá de las categorías de productos o servicios en las que están registradas, y por lo tanto, pueden oponerse legalmente al uso de su marca por terceros en cualquier otra categoría.

En un estudio pionero, Peterson et al. (1999) aplicaron los conceptos de tipicidad y dominio para valorar el grado de renombre de un número de 28 marcas, con una encuesta a 464 individuos. En el cuestionario se utilizaron las preguntas sugeridas por Simonson (1995). Los resultados de esta investigación son exploratorios y más bien permiten ilustrar la relevancia del tema. En la literatura académica no hemos

\footnotetext{
${ }^{4}$ Ley 17/2001 de 7 de diciembre, de marcas (BOE 8 de diciembre de 2001, núm. 294).

${ }^{5}$ Las distintas legislaciones utilizan definiciones muy distintas desde la perspectiva conceptual de marketing. Por ejemplo, la FTDA norteamericana de 1995 utiliza el término "marca famosa". La OMPI y la última resolución de la OMC - Organización Mundial del Comercio - utilizan el término "marca notoriamente conocida , mientras que la Primera Directiva Comunitaria a este respecto las denomina "marcas reputadas y distintivas". La ley española utiliza claramente el concepto de "marca renombrada".
} 
encontrado ningún trabajo posterior que profundice en metodologías cuantitativas de parametrización y/o cuantificación del renombre de marca. En España, el Foro de Marcas Renombradas Españolas llevo a cabo un estudio amplio de renombre de marcas españolas en el año 2007, utilizando la metodología de Peterson et al. (1999). El estudio valoró el renombre de las principales marcas españolas - un total de 176 marcas - en 118 categorías de productos y servicios, con entrevistas a una muestra de 4.800 individuos (público general) seleccionados aleatoriamente (ver Cerviño y Baena, 2009). El análisis de las marcas se realizó tanto de manera global como por categoría de producto. A efectos ilustrativos recogemos en la siguiente tabla $\left(n^{\circ} 1\right)$ el análisis realizado para las 23 marcas de cadenas de confección y moda.

\section{Tabla 1}

Tipicidad y Dominio de una Selección de Marcas de Cadenas de Moda y Confección

\begin{tabular}{|c|c|c|c|c|c|c|c|c|c|c|}
\hline Columna 1 & Columna 2 & Columna 3 & Columna 4 & Columna 5 & Columna 6 & Columna 7 & Columna 8 & Columna 9 & Columna 10 & $\begin{array}{l}\text { Columna } 11 \\
\end{array}$ \\
\hline $\begin{array}{c}\text { CADENAS DE MODA, CONFECCIÓN Y TEXTIL } \\
\text { Categoría potencial }\end{array}$ & $\begin{array}{c}\text { Marca } \\
\text { analizada }\end{array}$ & $\begin{array}{c}\text { Tipicidad } \\
(\%)\end{array}$ & $\begin{array}{c}\text { Dominio } \\
(\%)\end{array}$ & $\begin{array}{c}\text { La marca objetivo fue } \\
\text { la mas frecuentemente } \\
\text { citada }\end{array}$ & \begin{tabular}{|c|} 
Dominio \\
marca más \\
frecuent. citada
\end{tabular} & $\begin{array}{c}\text { Primera } \\
\text { marca }\end{array}$ & \begin{tabular}{|c|} 
Domino \\
segunda \\
marca
\end{tabular} & $\begin{array}{c}\text { Segunda } \\
\text { marca }\end{array}$ & $\begin{array}{l}\text { Ratio de } \\
\text { dominio }\end{array}$ & $\begin{array}{l}\text { Dominio Relativo } \\
\text { de Marca Objetivo }\end{array}$ \\
\hline \begin{tabular}{|l} 
Cadena moda \\
\end{tabular} & Zara & 95,2 & 70,5 & $\mathrm{si}$ & 70,5 & Zara & 22,6 & Mango & 3,1 & 3,1 \\
\hline Trajes para novias & Pronovias & 93,3 & 74,4 & si & 74,4 & Pronovias & 8,5 & Rosa Clara & 8,8 & 8,8 \\
\hline Cadena moda & Cortefiel & 97,3 & 50,3 & no & 70,5 & Zara & 19,5 & Springfield & 3,6 & 0,7 \\
\hline Cadena moda femenina & Mango & 87,7 & 22,6 & no & 70,5 & Zara & 22,6 & Mango & 3,1 & 0,3 \\
\hline Cadena moda joven masculina & Springfield & 78,6 & 27,1 & no & 39,6 & Zara & 27,1 & Springfield & 1,5 & 0,7 \\
\hline Cadena de ropa de aventura & Coronel Tapioca & 58,8 & 39,0 & si & 39,0 & Coronel Tapioca & 3,6 & Decathlon & 10,8 & 10,8 \\
\hline Cadena moda diseño & Adolfo Dominguez & 95,8 & 12,4 & no & 52,1 & Zara & 15,6 & Massimo Dutti & 3,3 & 0,2 \\
\hline Cadena moda & Massimo Dutti & 80,0 & 18,8 & no & 70,5 & Zara & 19,5 & Springfield & 3,6 & 0,3 \\
\hline Cadena moda joven femenina & Bershka & 62,0 & 27,5 & no & 70,5 & Zara & 27,5 & Bershka & 2,6 & 0,4 \\
\hline Cadena moda joven femenina & Stradivarius & 61,8 & 20,0 & no & 55,7 & Zara & 27,5 & Bershka & 2,0 & 0,4 \\
\hline Bisutería diseńo y complementos & Tous & 65,1 & 19,5 & si & 19,5 & Tous & 1,8 & Agata & 10,8 & 10,8 \\
\hline Cadena de ropa de niñó & Mayoral & 71,1 & 11,7 & no & 21,4 & Zara & 17,4 & Prenatal & 1,2 & 0,5 \\
\hline Cadena lencería femenina & Women's Secret & 55,7 & 17,1 & si & 17,1 & Women's Secret & 6,3 & Intimissimi & 2,7 & 2,7 \\
\hline Cadena moda joven masculina & Pull and Bear & 62,0 & 13,2 & no & 39,6 & Zara & 27,1 & Springfield & 1,5 & 0,3 \\
\hline Camisería a medida & Artesanos Camiseros & 76,5 & 4,1 & si & 4,1 & rtesanos Camisero & 2,3 & Qellos & 1,8 & 1,8 \\
\hline Cadena moda diseño & Roberto Verino & 76,9 & 2,5 & no & 70,5 & Zara & 22,4 & Mango & 3,1 & 0,0 \\
\hline Cadena de trajes para hombre & Milano & 44,6 & 6,6 & no & 17,9 & Massimo Dutti & 13,1 & Emidio Tucci & 1,4 & 0,4 \\
\hline Cadena moda masculina & Armand Bassi & 54,9 & 0,4 & no & 30,4 & Zara & 19,5 & Springfield & 1,6 & 0,0 \\
\hline Cadena moda femenina & Sfera & 39,2 & 2,5 & no & 70,5 & Zara & 22,6 & Mango & 3,1 & 0,0 \\
\hline Camisería de diseño & Custo & 41,0 & 2,2 & no & 5,1 & Massimo Dutti & 3,1 & Emidio Tucci & 1,6 & 0,4 \\
\hline Cadena textil hogar y decoración & Zara Home & 43,2 & 7,8 & si & 7,8 & Zara Home & 7,3 & Casa & 1,1 & 1,1 \\
\hline Cadena textil hogar y decoración & Ka internacional & 8,8 & 0,7 & no & 7,8 & Zara Home & 7,3 & Casa & 1,1 & 0,1 \\
\hline Grandes almacenes & El Corte Inglés & 88,0 & 78,8 & si & 78,8 & El Corte Inglés & 39,1 & Carrefour & $\begin{array}{l}2,1 \\
2,0\end{array}$ & 2,0 \\
\hline Medias del Sector & & 60,8 & 19,2 & & 39,5 & & 14,3 & & 3,1 & 1,9 \\
\hline
\end{tabular}

La primera columna contiene las 23 categorías de productos objeto de análisis. La segunda columna contiene las marcas utilizadas como representativas y/o identificadas con cada categoría. Las columnas 3 y 4 contienen los porcentajes de tipicidad y dominio. La tipicidad significa en esta tabla el porcentaje de encuestados que respondieron con la categoría de producto seleccionada (o similar) cuando se les sugería el nombre de marca. El dominio significa el porcentaje de participantes que respondieron con la marca objeto de análisis cuando se les sugería la categoría de producto seleccionada. Por ejemplo, cuando a la muestra se le sugirió la marca Coronel Tapioca, un $58.8 \%$ de los participantes respondieron con la categoría de "cadena de ropa de aventura o ropa de aventura". Cuando se les sugirió la categoría objetivo de "Cadena de ropa de aventura”, el 39\% de los participantes respondieron "Coronel Tapioca”. Así, el grado de tipicidad de la marca Coronel Tapioca es de 58,8\% y el de dominio en la categoría del 39\%. 
La columna quinta indica si cada marca objeto de análisis fue las más frecuentemente mencionada para su categoría particular de producto. La columna 6 refleja el porcentaje de respuesta recibido por la marca más frecuentemente menciona en la categoría dada de producto. La columna 7 recoge la marca más mencionada en la categoría. La columna 8 el dominio de la segunda marca más citada y la columna 9 cuál ha sido la segunda marca más citada. La columna 10 muestra el ratio entre el porcentaje de la marca más frecuentemente mencionada en una categoría de producto y el porcentaje de la segunda marca más frecuentemente mencionada. Así, por ejemplo, Coronel Tapioca fue la marca más frecuentemente mencionada dentro de la categoría de ropa de aventura, y fue mencionada 10,8 veces más que la segunda marca más mencionada (en este caso, Decathlon). Finalmente, la columna 11 recoge el dominio relativo de la marca objeto de análisis respecto a la marca más citada o si esta es la más citada, respecto a la segunda. Para aquellas marcas “objetivo” más citadas, esta columna será idéntica a la columna 10.

Este análisis general puede representarse gráficamente en un mapa de posicionamiento de las marcas respecto a las medidas de dominio y tipicidad alcanzado en la muestra. En el siguiente gráfico 3 recogemos estos datos.

Gráfico 3

Posicionamiento de Marcas en función de su Tipicidad y Dominio

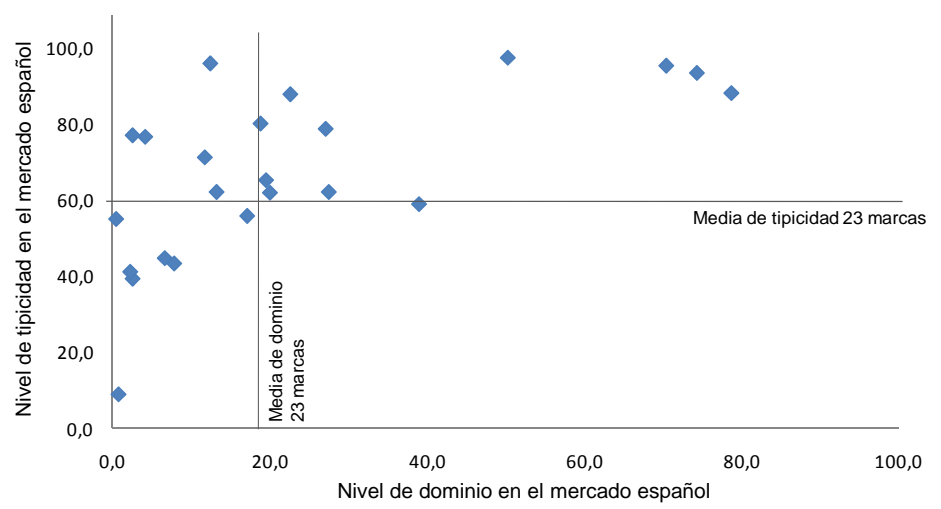

Fuente: Foro de Marcas Renombradas Españolas. Estudio sobre el Renombre de las Marcas Españolas (2007)

Evidentemente, los resultados de esta investigación son exploratorios y más bien ilustrativos. Aun así, los resultados, según indica Peterson et. al. (1999), pueden ser lógicamente intuitivos y permiten analizar algunos de los criterios enfatizados en las respectivas legislaciones en materia de protección de marcas famosas y renombradas. De los resultados se desprende que la tipicidad excede al valor del dominio de marca. En realidad, la media del porcentaje de tipicidad se 
sitúa en un 60,80 (desviación típica del 18\%), casi tres veces más que la media del porcentaje de dominio, 19,20\% (desviación típica 16,5\%). También, se puede observar que muchas marcas poseen una tipicidad relativamente elevada, pero con muy bajo dominio. De las 11 marcas que muestran niveles de tipicidad superiores al $70 \%$, cinco de ellas no superan la media de dominio del grupo de marcas analizado, situado en un 19,2\% (Adolfo Domínguez, Massimo Dutti, Mayoral, Artesanos Camiseros y Roberto Verino), y a excepción de Artesanos Camiseros, ninguna de ellas es la más frecuentemente citada.

A partir de estos datos, se puede argumentar que aquellas marcas que posean niveles altos de tipicidad y dominio (Zara, Pronovias, El Corte Inglés, Cortefiel, Mango, etc.) son, sin lugar a dudas, renombradas desde la perspectiva comercial y legal. En este sentido, la valoración de "niveles altos" se refiere a niveles que superan un porcentaje (relativo o absoluto) dado. En cualquier caso, que una marca, por ejemplo, Artesanos Camiseros, con alta tipicidad (76,5\%) pero bajo dominio (4,1\%), pueda ser calificada como famosa o renombrada dependerá de su posición relativa frente a otras marcas de la categoría. En ciertas situaciones, será importante considerar el ratio de dominio de la marca (columna 11). Por lo tanto, si la fama o el renombre se define en relación a la media de las categorías de producto, un ratio de dominio bajo podría ser aceptable para determinar el renombre de la marca. En este sentido, Artesanos Camiseros, a pesar de tener un dominio bajo, debido principalmente a estar muy posicionada en una categoría muy de nicho -camisas a medida- y por lo tanto, no muy popular en cuanto a su espectro de mercado, presenta un ratio de domino relativo alto: un 1,8. La segunda marca en su categoría, la cadena Q-Ellos presenta un índice de dominio del 2,3 frente al 4,1 de Artesanos Camiseros, y por lo tanto, un ratio de dominio del 0,6. En este sentido, y si nos centramos en esta categoría del sector de cadenas de moda y textil, la marca Artesanos Camiseros disfruta de un incuestionable liderazgo en cuanto a tipicidad y dominio, por lo que en este contexto, podría ser considerada renombrada. Evidentemente un aspecto clave en todo este análisis es la correcta definición de la categoría de la marca.

Por último cabe analizar brevemente un aspecto relacionado con el renombre de las marcas, tal como es el de la dilución causada por terceros. El titular de una marca renombrada puede oponerse a que terceras empresas utilicen dicha marca en otras categorías de productos, aunque el titular original no tenga registrada su marca en dichas categorías. Dado el valor de la marca renombrada, la legislación vigente entiende que puede haber un aprovechamiento indebido del valor, imagen y reputación de la marca renombrada así como, y más importante para el titular de la marca, que se pueden generar situaciones de menoscabo del prestigio y del carácter distintivo de la marca renombrada. En este contexto, y para defender el valor de su marca y solicitar los daños y perjuicios pertinentes, el titular de la marca renombrada debe, en primer lugar, probar su renombre y en segundo lugar, probar 
y cuantificar la dilución de la marca. En los párrafos anteriores hemos presentado el procedimiento para la cuantificación del renombre. En los siguientes párrafos analizaremos brevemente los retos que supone probar y cuantificar la dilución.

Roedder, Loker y Joiner (1998) definen la dilución de marca como todo cambio negativo en las creencias y actitudes que el consumidor tiene de una marca. En la literatura de marketing, el estudio de la dilución de marca se ha centrado principalmente en analizar como las extensiones de marca pueden, en mayor o menor medida, diluir las creencias y actitudes asociadas a la marca (Keller y Aaker, 1992; Farquhar, Han, Herr y Ijiri, 1992; Loken y Roedder, 1993; Leong, 1997; Gürhan-Canly y Maheswaran, 1998; Morrin, 1999).

Sin embargo, la dilución relacionada con el aspecto jurídico de la marca notoria o renombrada se centra en medir los efectos negativos sobre el valor de marca que se originan del uso no autorizado de una marca famosa o renombrada (o una marca similar) por un tercero (Morrin y Jacoby, 2000). La investigación académica ofrece algunos estudios, no muchos, sobre la medición de la dilución (Morrin y Jacoby, 2000; Morrin, Lee y Allenby, 2004) y sus determinantes (Morrin, Lee y Allenby, 2006), realizados a través de experimentos con grupos de individuos expuestos a diferentes estímulos publicitarios y marcarios. Jacoby (2008) presenta un resumen de las consideraciones que se deben tener en cuenta al momento de medir las distintas manifestaciones de la dilución de marcas renombradas, enmarcándose en los requerimientos de la legislación norteamericana en la materia (Trademark Dilution Revision Act de 2006). Desde la perspectiva de la marca renombrada, la dilución se puede manifestar como mínimo de dos maneras diferentes: a) reduciendo el nivel de preferencia y actitudes a la hora de evaluar la marca, y b) reduciendo el nivel de unicidad, especificidad, evocación y notoriedad de la marca. En su trabajo seminal, Simonson (1995) definió cada una de ellas como dilución de valoración (a), y dilución de tipicidad (b). La distintas metodologías empíricas para valorar la dilución de valoración (tipo a) se centran en estudios sobre medidas de valoración de atributos de marca (ver Loken y Roedder, 1993). Las metodologías para medir la dilución de tipicidad (tipo b) analizan medidas de reconocimiento y memoria, tales como la notoriedad espontánea y notoriedad sugerida, análisis de evocación simbólica de la marca al ser expuesta al consumidor, y análisis de posicionamiento de similitud y preferencias de marcas (Morrin, 1999).

En línea con lo anteriormente expuesto, es preciso mencionar que al cierre de este artículo, los autores no identificaron ningún estudio donde se mida o valore financieramente la pérdida de valor que sufre el capital de una marca renombrada debido a una situación de dilución de marca, bien por uso indiscriminado de la marca por un tercero o por copias o imitaciones. Una investigación de este tipo permitiría proveer de elementos adicionales de juicio en las demandas legales que se presentan por dilución de marcas, en donde se podría estimar financieramente el perjuicio generado por las marcas imitadoras. 


\section{LA INTERNACIONALIZACIÓN DE LA MARCA}

La gestión de marcas genera capacidades (activos intangibles) que nutren el concepto de brand equity (capital de marca) y son de carácter tácito. Este tipo de conocimiento está relacionado con el contexto en el que se ha generado. En este sentido, la creación y explotación de una imagen de marca en el exterior necesita que se generen conocimientos específicos de contexto (international brand equity) lo que puede ser un factor determinante de la creación de filiales en el exterior. La cercanía a la demanda y al canal de distribución local, la gestión, protección y apoyo a la marca puede constituir factores determinantes en la creación y localización de filiales en el exterior, es decir, de la realización de inversiones directas en el exterior. Así, la incertidumbre sobre protección legal y credibilidad institucional son factores asociados a la localización de inversión directa en el exterior de carácter comercial. La protección institucional (legal, organizativa y de tribunales de justicia) de los activos comerciales codificados (marcas y nombres comerciales) reducen los costes de transacción y facilitan su utilización a través del mercado (exportaciones, franquicias). La senda internacional de la marca está asociada a los denominados modos de entrada en el exterior, es decir está asociada a los negocios internacionales realizados a través de: exportaciones con marca propia; franquicias; licencias, filiales comerciales en el exterior; filiales de producción y venta en el exterior. Sin embargo, cuando el volumen de actividad en el exterior es relevante y la eficacia de la marca, asociada a su producto es positiva, puede ser conveniente la realización de inversión directa en el exterior, sobre todo si afecta a la imagen y reputación de la empresa, es decir, internalizar actividades en el exterior cuando la marca es un activo estratégico en el proceso de internacionalización.

La marca es generadora de reputación de la empresa (Onkovisit y Shaw, 1989; Aaker, 1991). Asimismo, las marcas renombradas a nivel internacional influyen positiva y significativamente en la imagen de su país de origen ${ }^{6}$. Así se ha mostrado en el caso español en el que las marcas comerciales son insumos de la imagen de España en el exterior (Cerviño et al. 2005). La reputación de una marca depende de la imagen que proyecte en cada país. Una mala imagen en un país puede afectar negativamente en otros. Es decir, la marca es un activo interdependiente por lo que se requiere una coordinación centralizada, internalizándose su uso (Madhok, 1998). La marca crea capital relacional mediante

${ }^{6}$ Los sectores con los que se identifica España en el mundo, además del turismo, son : moda y confección (Inditex, Mango, Cortefiel), alimentación y bebidas (Freixenet, Torres, vino en general, Borges, Carbonell) calzado (Panama Jack), telecomunicaciones (Telefónica), energía (Repsol YPF, Iberdrola, Endesa, Gas Natural) banca y seguros (Santander, BBVA, Mapfre), infraestructuras (Ferrovial, ACS, Albertis..), materiales de construcción (Porcelanosa, Silestone, Roca, Fagor, Teka) hoteles (Sol-Meliá, NH, Barceló). 
la confianza y reputación de la empresa a través de su interacción con agentes (es un capital entrelazado de ámbito exterior).

España es considerada país desarrollado de acuerdo a diferentes indicadores. Atendiendo a la denominada teoría de la senda de la inversión internacional (Investment Development Path, IDP) existen cinco grupos de países: los tres primeros son menos desarrollados y, a diferentes niveles de desarrollo, se caracterizan por ser receptores netos de inversión directa extranjera (diferencia en términos de stock entre la salida y la entrada). España pertenece al cuarto grupo (Durán y Úbeda, 2001, 2005) y su distancia respecto al quinto o más desarrollado se debe a su menor dotación de intangibles, es decir, a su menor incidencia de la innovación en la dotación de capital tecnológico, comercial y directivo. Consecuentemente una cartera mayor de marcas renombradas asociadas al control (total o compartido) de canales de distribución y comercialización internacional de sus productos y servicios reducirá el gap con los países más desarrollados.

En los estudios relativos a la empresa exportadora se concluye también que las empresas que crean filiales comerciales en el exterior poseen una mayor dotación de activos intangibles y de disponibilidad de recursos que el resto de empresas exportadoras (Rialp, 1999; Plá, 1999). En esta misma línea se argumenta que en la decisión de inversión directa en el exterior de carácter comercial son factores determinantes los gastos en publicidad, el capital relacional (fabricante, distribuidor), el servicio pre/postventa, el grado de diferenciación de productos (Rialp, 1999) y la imagen de marca internacional (Plá, 1999; Durán y Úbeda, 2004).

Para una muestra de 965 empresas exportadoras españolas, de las cuales 188 eran multinacionales) que realizaron 1.954 modos de entrada en mercados exteriores y controlando por la experiencia internacional, dotación de activos tecnológicos y tamaño se concluye que la marca es un factor determinante de la IDE, existiendo una relación positiva entre esta variable y la exportación con marca propia, gastos de publicidad y campañas sistemáticas de publicidad en el exterior así como con la experiencia y diversificación geográfica de las exportaciones (Durán y Úbeda, 2004). De las empresas exportadoras el 31 \% venden el exterior con marca propia y utilizan sistemáticamente campañas de publicidad a nivel internacional.

\section{EL VALOR FINANCIERO DE LAS MARCAS: LA NUEVA NORMA ISO 10668}

La valoración de marcas es, sin duda, relevante como lo es en general la valoración de intangibles no solo por cuantificar estos capitales económicos sino por las exigencias contables, fiscales, financieras y legales derivadas de esta creciente 
importancia económica (Salinas, 2007a). En la tabla 2 ofrecemos una síntesis de las razones y aplicaciones de la valoración de marcas (ver Tabla 2) que ponen de manifiesto la complejidad de la valoración de este tipo de activos. Asimismo, anteriormente hemos señalado la ausencia de modelos que permitan cuantificar la pérdida de valor financiero sufrido por una marca en una situación de dilución generada por un tercero.

Tabla 2

Motivaciones y Aplicaciones de la Valoración de Marcas

\begin{tabular}{|c|c|}
\hline Orientación Estratégica & Orientación Financiera \\
\hline $\begin{array}{l}\text { - } \begin{array}{l}\text { Racionalización de las cartera de } \\
\text { marcas }\end{array} \\
\text { - Asignación de recursos } \\
\text { financieros para actividades de } \\
\text { Marketing } \\
\text { - } \begin{array}{l}\text { Planificación y control de } \\
\text { resultados }\end{array} \\
\text { - Medición de la eficacia financiera } \\
\text { de las acciones de comunicación } \\
\text { en marca } \\
\text { - Internacionalización y extensión } \\
\text { de marcas } \\
\text { - Adquisición y/o venta de marcas } \\
\text { - Gestión de marcas y desarrollo de } \\
\text { nuevos productos } \\
\text { Comunicación interna (matriz- } \\
\text { filiales) y con accionistas }\end{array}$ & 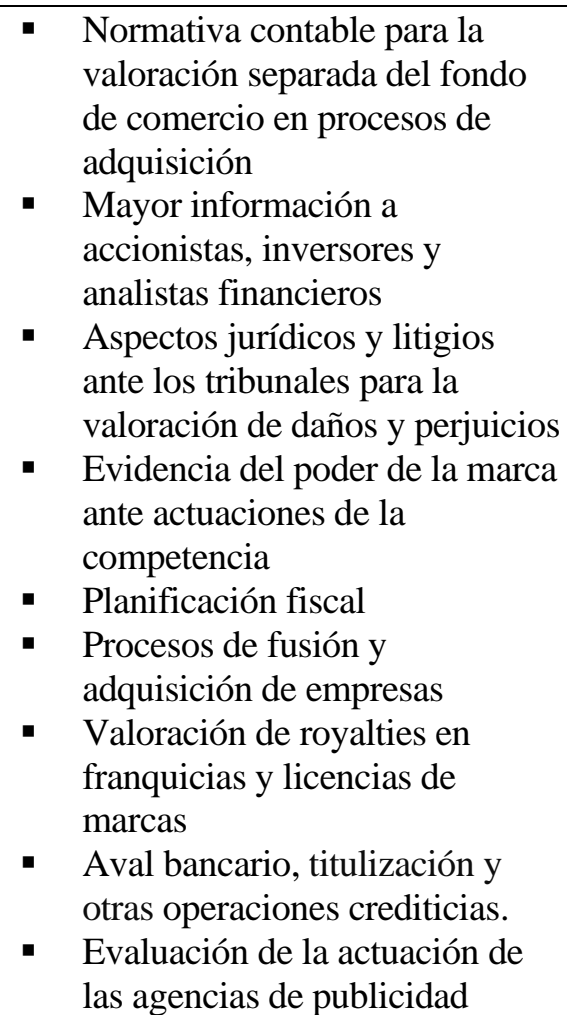 \\
\hline
\end{tabular}

Fuente: Elaboración propia.

Ahora bien, en la actualidad existen numerosos métodos de valoración de marcas, si bien, no hay un consenso total y absoluto entre las diferentes consultoras, auditoras, especialistas en valoración y académicos sobre cuál es el método más objetivo y fiable. Por otro lado, estamos asistiendo a una proliferación de rankings de "valoración económica de marcas" con metodologías muy diversas y que conducen a 
estimaciones de valor muy diferentes. Evidentemente, esto plantea importantes incógnitas acerca de la fiabilidad de algunos de estos métodos, generando mucha incredulidad en el ámbito empresarial y legal. Incluso diversas consultoras que utilizan metodologías similares y de amplia divulgación, llegan a conclusiones muy dispares. Cabe señalar, por ejemplo, que el último ranking de Interbrand de valoración económica de marcas: “The Best Global Brands 2011", estima el valor de la marca Zara en unos 8.065 millones de dólares americanos. Sin embargo, el más reciente informe de Millward Brown Optimor “Top 100 Most Valuable Global Brands” estima para esta misma marca un valor de 8.986 millones de dólares americanos, es decir, casi mil millones más (un 11,4\% de diferencia). La cita de Jeremy Bullmore, Presidente del mayor grupo de publicidad y comunicación el mundo - WPP, resume de forma ejemplar estos desacuerdos: "El único momento en el que puedes estar seguro del valor de tu marca es justo cuando la acabas de vender" (citado en Rattray, 2002).

Si a estas discrepancias también consideramos que muchas de estas grandes consultoras de valoración de marcas dependen de grupos de comunicación líderes, como FutureBrand, que es parte de IPG, Interbrand que es parte de Omnicom, o Millward Brown Optimor, que es parte del grupo WPP, se añade además cierta falta de independencia en la evaluación del activo cuya comunicación o gestión es muchas veces responsabilidad del mismo grupo que valora la marca.

En este contexto nos referimos a la nueva norma ISO 10668 "Brand Valuation Requirements for monetary brand valuation" que supone un importante avance a la hora de establecer unos requisitos básicos que deben cumplir los proveedores de valoración de marcas, tanto en valoraciones con fines contables, fiscales o legales, como valoraciones para fines de gestión estratégica de la marca (ver tabla 2). La norma surge como un trabajo nacional de DIN, la rama alemana de ISO. Esta iniciativa se eleva en 2007 a nivel internacional y se configura un Comité Técnico (ISO TC 231) compuesto por representantes y expertos multidisciplinares de aquellos países que participan en la iniciativa, publicándose la norma en septiembre del 2010. Hay que señalar que antes de la aprobación de la ISO 10668, existían ya diversas normas de valoración de intangibles, incluido marcas, por parte de organizaciones como FASB, IASB, OCDE y el International Valuation Standard Council (IVSC). Ahora bien, estas normas están claramente redactadas desde una perspectiva principalmente contable, con algún aspecto financiero, obviando aspectos claves para poder valorar una marca como, por ejemplo, evaluar su "capital de marca” (brand equity), la percepción entre consumidores y grado de influencia de la marca, riesgos y aspectos legales, como por ejemplo la dilución de la marca, etc. La nueva norma ISO recoge el conocimiento de expertos multidisciplinares, que van desde financieros, especialistas en marketing e investigación de mercados y abogados.

Desde la perspectiva económica financiera, la norma recoge tres enfoques de valoración, principalmente centrándose en el enfoque de beneficios (ver gráfico 4). El 
enfoque de beneficios valora la marca como valor actual de los beneficios esperados atribuibles a dicho activo durante su vida útil. Este enfoque coincide con el empleado comúnmente en la valoración de empresas (Descuento de Flujos de Caja o similar). Dentro de este enfoque se recogen principalmente cuatro métodos: Precio primado, premium de volumen, separación de beneficios y el método de royalties.

El método del precio primado (diferencial respecto a un producto sin marca) es ciertamente muy fácil de utilizar pero presenta una gran limitación y es que en términos económicos es difícil plantearse la existencia de un producto sin marca y en realidad hoy la Marca de Distribuidor o "marca blanca" ya es una marca en sí. El método de Premium de volumen (diferencial de volumen) al estar ligado al anterior, presenta también serias limitaciones. El método "Income-Split" trata de identificar el valor económico generado por la empresa en exceso al retorno exigido al capital empleado y, mediante investigación con clientes y análisis competitivo, y técnicas de análisis estadístico, aislar cuánto valor es generado por la marca y cuánto por otros factores. Ciertamente este es el método más complejo y más utilizado por las principales consultoras de valoración de marcas, y también, el método que genera mayor diversidad en cuanto a las valoraciones. Por otro lado, las distintas consultoras internacionales utilizan su metodología como "una caja negra" (metodologías protegidas intelectualmente), parecida a la filosofía utilizada por las agencias de rating para valorar activos financieros, por lo que el usuario final no accede a los detalles específicos y ponderaciones realizadas en el proceso de valoración. Lamentablemente, y si bien la norma ISO ofrece unas indicaciones generales, no entra en detalle en definir una metodología que permita valorar la fortaleza de la marca y su contribución exacta a los flujos de caja generados.

Gráfico 4

Método de Valoración de Marcas según la ISO 10668

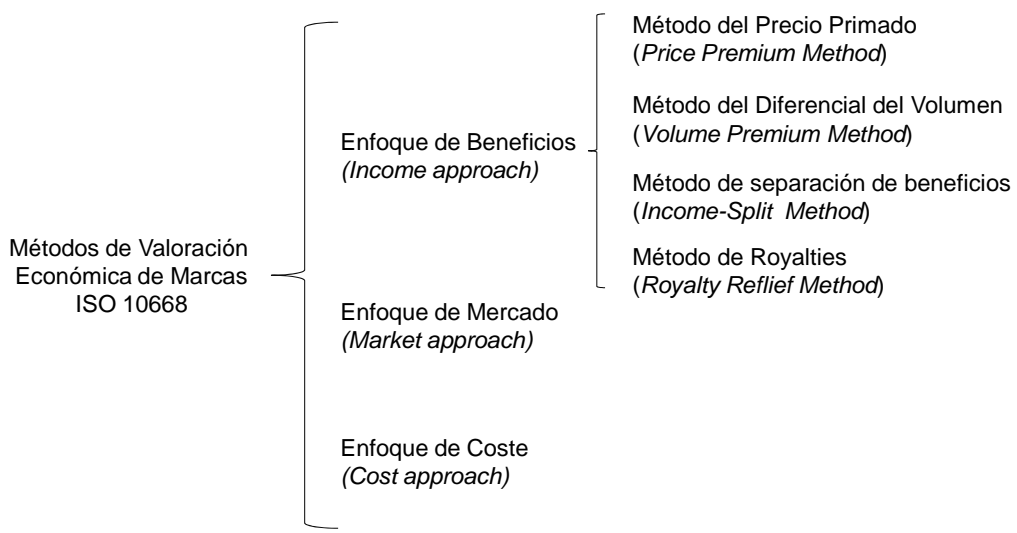


Por último, el método de royalties, conocido en inglés como "Royalty Relief” o "Relief from Royalty" se basa en el supuesto que una compañía no posee los derechos de propiedad de la marca y necesitará licenciarla de un tercero. El valor se establece así como el valor actual del flujo de royalties generados si el negocio tuviese que pagar dicho royalty. La clave de este método es establecer la tasa de royalty apropiada. Para ello se utilizan bases de datos que contienen datos históricos de tasas de royalty internacionales para la industria y el producto específicos que sirven de comparación y benchmark, dando lugar al procedimiento definido como "Análisis Comparativos de Acuerdos de Royalties" realizados en el mercado en transacciones libres - Comparable Uncontrolled Transaction - CUT (ver de Souza, 1997). Dado que existen diversas bases de datos muy fiables sobre los tipos de royalties en distintos sectores y productos, este método es el más aceptado por instituciones jurídicas y organismos fiscales, como por ejemplo el Internal Revenue Service (IRS) de los EE.UU, que utiliza este método para la fijación el tipo de royalties internos de marcas en operaciones de precios de transferencia entre empresas (Doonan y Tien, 2002; Fraedrich y Bateman, 1996).

Los otros dos enfoques de valoración son Mercado (aplicar múltiplos de transacciones de compra-venta de marcas, algo que no es muy habitual), y Coste, que trata de estimar el coste de "recrear" la marca si se tuviese que lanzar de nuevo o calcular todo lo invertido en crear la marca. Estos dos enfoques son realmente limitados y solo deben usarse en circunstancias muy concretas. Por ejemplo, para valorar una marca con pocos meses de vida y donde es difícil estimar sus resultados futuros, en esta situación el enfoque de coste puede ser un buen método de partida.

En resumen, la nueva norma ISO 10668 permite esclarecer y delimitar la "jungla" de metodologías de valoración de marca existentes hasta la fecha. Como bien señala Salinas (2007a) en su libro de valoración de marcas "desde que Rupert Murdoch incluyó los valores de las cabeceras de sus periódicos en el balance de su grupo de comunicación, han proliferado cerca de medio centenar de modelos de valoración de marcas propuestos por académicos y proveedores comerciales”, la gran mayoría de ellos desarrollados en los últimos diez años. Como señalamos anteriormente, y para añadir más complejidad al tema, los enfoques académicos y profesionales utilizan en ocasiones modelos y parámetros diametralmente diferentes y basados en distintos conceptos de marca. Todo esto genera una falta de confianza en las empresas y analistas financieros. En un estudio realizado entre las principales corporaciones alemanas, y publicado en 2001, se concluye que uno de los motivos fundamentales para no llevar adelante una valoración de marcas es la falta de un método apropiado y/o un consenso sobre el preferido (Salinas, 2007b). Ahora bien, la ISO 10668 no es todo lo ambiciosa que cabría esperar, estableciendo los tres principales métodos de manera muy superficial y con poco detalle. Evidentemente es un avance en armonizar criterios, y como toda norma ISO, es revisable y seguramente a lo largo del tiempo se vaya actualizando y mejorando. Si bien no hay todavía un consenso definitivo, si que 
podemos afirmar que en el ámbito fiscal, financiero y legal (que es donde más valoraciones de marca se realizan), el método del royalties es el más utilizado y con el que existe un mayor acuerdo generalizado. En este sentido, las principales consultoras de valoración de marcas debería contrastar las valoraciones obtenidas con sus metodologías de "módulos opacos y poco transparentes" con las obtenidos por el método de royalties. De esta manera, se ofrecería al mercado un rango adecuado del valor de marca a partir de dos metodologías complementarias, generando más credibilidad y confianza en las valoraciones emitidas.

\section{CONSIDERACIONES FINALES}

La marca puede ser vista como un vehículo de relación y comunicación entre la empresa y el mercado: con sus clientes/consumidores, con sus proveedores y con los inversores (prestamistas y accionistas). Es decir, la marca facilita la relación con el mercado de productos, de factores y financiero. La marca ayuda a identificar productos y su calidad y a diferenciarlos de otros semejantes. La marca sintetiza información e imprime un carácter distintivo a los productos que representa, lo que dificulta su grado sustitución, aunque puede ser incentivador de la imitación en entornos permisivos. La marca tiene utilidad para el consumidor y tiene una condición valorativa que permite fijar un precio de los productos más allá de sus costes de producción y de sus características físicas. La marca crea valor. La marca crea capital relacional (entrelazado) mediante la confianza y reputación de la empresa a través de su interacción con agentes.

La marca es el activo nuclear del capital comercial de la empresa; puede constituir una palanca para la distribución y venta de los productos, ser generadora de rentas y por tanto contribuir a la creación de valor, lo que le confiere una clara dimensión financiera, y ser fuente de ventajas competitivas sostenibles para la organización. Asimismo, por su carácter de activo intangible, con una estrecha relación con conocimientos tácitos de naturaleza comercial, su protección institucional le confiere dimensiones específicas de naturaleza jurídica y legal.

Tradicionalmente, la marca estaba asociada a los bienes de consumo. Ahora bien, en una economía tan competitiva y globalizada la marca se ha revelado también prioritaria para todo tipo de sectores o industrias, comenzando hace ya varios años en el área de servicios y más recientemente en el área industrial. Incluso, la marca está asumiendo una importancia estratégica creciente en aspectos institucionales, como es el caso de la "Marca País" (o sus derivadas: Marca Ciudad, Marca Región, Marca de Origen Geográfico), siendo un hecho cada vez más evidente la relación bidireccional entre las marcas comerciales y la imagen de la marca país.

Dada la importancia estratégica del activo marca, es necesario entender que la responsabilidad de su gestión va más allá del departamento de marketing. En el 
proceso de creación y gestión de marcas deben participar las demás áreas organizativas de la empresa, dado que todas tienen, en mayor o menor medida, una responsabilidad en su creación, imagen y posicionamiento, y en última instancia, en la creación y gestión de su valor reputacional. Es lo que Urde (1999) define como una “Orientación a la Marca” de toda la organización.

En este contexto de importancia creciente del activo marcario, la investigación académica sobre las marcas es ciertamente extensa, cubriendo un amplio abanico de temas y problemáticas. En el Anexo I de este trabajo se recogen las áreas ampliamente investigadas. Ahora bien, un mercado tan dinámico y cambiante como el actual, presenta nuevas problemáticas y dimensiones en la gestión de marcas. Además, por su novedad, estos temas han sido escasamente investigados en la literatura académica. En este trabajo se analizan algunas de estas problemáticas, y en concreto, la problemática de las marcas “durmientes”, la parametrización del concepto legal de marca renombrada, la valoración de la dilución de marca generada por terceros, la internacionalización de la marca y el desconcierto actual en el área de la valoración económica de las marcas y las posibles soluciones que ofrece la nueva norma ISO 10668. Las respuestas a estas problemáticas tienen que venir del ámbito legal, financiero y de la investigación comercial.

Respecto a las "marcas durmientes", se podría afirmar que las legislaciones actuales en materia de marca no están lo suficientemente actualizadas para dar respuesta a esta creciente problemática. El valor residual de las marcas que han sido notorias o renombradas va más allá de los cinco años que las respectivas legislaciones estiman para la caducidad de la marca.

En relación al concepto legalmente establecido de "marca renombrada", la literatura de marketing no ha establecido todavía modelos o parámetros concluyentes que permitan cuantificar cuando una marca es renombrada o solamente notoria. Los escasos trabajos en esta área son ciertamente exploratorios y serán necesarias nuevas investigaciones que profundicen en metodologías que permitan delimitar correctamente este concepto. Relacionado con los aspectos de "marca durmiente" y "marca renombrada" subyace la problemática de la dilución del valor de marca. La literatura de marketing ha analizado extensamente este aspecto desde la vertiente de los fracasos en las extensiones de marca. Sin embargo, existe todavía una importante laguna sobre el análisis y cuantificación de la dilución de marca generada por terceros.

La internacionalización de las marcas es un aspecto ampliamente analizado en la literatura, si bien, desde una perspectiva mucho más descriptiva que causal. Son todavía escasos los trabajos que empíricamente relacionen el valor de las marcas con los modos y formas de entrada en mercados internacionales, el desempeño en términos de rentabilidad y cuotas de mercado de la actividad exportadora, y su relación con la competitividad de los países.

Por último, el trabajo analiza la proliferación de métodos de valoración económica de marcas y la consiguiente publicación de diversos rankings de valor de marcas, que 
conjuntamente generan mucha desconfianza e incredulidad en el ámbito empresarial, financiero y legal. Con objeto de establecer unos requisitos básicos normativos con una visión multidisciplinar del activo marca surge, a finales de 2010, la norma ISO 10668. Si bien la nueva norma no es todo lo ambiciosa que cabría esperar, permite esclarecer y delimitar la "jungla” de metodologías de valoración de marca existentes hasta la fecha. Asimismo, y con objeto de ofrecer al mercado un valor de marca los más objetivo y fiable posible, entendemos que el analista (investigador o consultora especializada) debería ofrecer el valor de marca obtenido a partir de las principales metodologías avaladas por la nueva norma ISO y no únicamente un único valor a partir de una única metodología. De esta manera, se ofrecería al mercado un rango adecuado del valor de marca, generando más credibilidad y confianza en las valoraciones emitidas

\section{BIBLIOGRAFÍA}

AAKER, D. (1991), Managing Brand Equity: Capitalizing on the Value of a Brand Name, The Free Press, New York, NY.

AAKER, D. (1996), "Measuring brand equity across products and markets", California Management Review, Vol. 38 (3), primavera, 102-120.

AAKER, D. (1996), Building Strong Brands, Free Press, Nueva York.

AAKER, D. (1997), "Should you take your brand to where the action is?, Harvard Business Review, 75 (septiembre-octubre), 125-143.

AAKER, D. (1999), "The malleable self: The role of self-expression in persuasion”, Journal of Marketing Research, Vol. 36, mayo, 45-57.

AAKER, D. (2004), Brand Portfolio Strategy: Creating Relevance, Differentiation, Energy, Leverage, and Clarity, Free Press, Glencoe, Illinois.

AAKER, D. y JACOBSON, R. (1994), "The financial information content of perceived quality", Journal of Marketing Research, Vol. 31, noviembre, 485493.

AAKER, D. y KELLER, K.L. (1990), "Consumer evaluations of brand extensions”, Journal of Marketing, Vol. 54, enero, 27-41.

AAKER, J.L., BENET-MARTÍNEZ, V. y BERROCAL, J.G. (2001), "Consumption symbols as carriers of culture: A study of Japanese and Spanish brand personality constructs”, Journal of Personality Psychology, Vol. 81 (3), 492-508.

AAKER, J.L., FOURNIER, S.M. y BRASEL, S.A. (2004), "When good brands do bad”, Journal of Consumer Research, Vol. 31, junio, 1-16.

AGGARVAL, P. (2004), "The effects of brand relationship norms on consumer attitudes and behavior”, Journal of Consumer Research, Vol. 31, junio, 87101. 
AGRAWAL, M.K. y RAO, R. (1996), "An empirical comparison of consumerbased measures of brand equity”, Marketing Letters, Vol. 7 (3), 237-247

AHLUWALIA, R.Z. y GÜRHAN-CANLI (2000), "The effects of extensions on the family brand name: An accessibility-diagnosticity perspective”, Journal of Consumer Research, Vol. 27, diciembre, 371-381.

AILAWADI, K.L., LEHMANN, D.R. y NESLIN, S.A. (2001), "Market response to a major policy change in the marketing mix: Learning from Procter \& Gamble's value pricing strategy", Journal of Marketing, Vol. 65, enero, 4461.

AMBLER, T. (2004), Marketing and the Botton Line, $2^{\mathrm{a}}$ edición, Financial Times, Prentice Hall, Londres.

AMBLER, T. y BARWISE, P. (1998), “The trouble with brand valuation”, Journal of Brand Management, Vol. 5, mayo, 367-377.

ANAND, B.N. y SHACHAR, R. (2004), "Brands as beacons: A new source of loyalty to multiproduct firms", Journal of Marketing Research, Vol. 41, mayo, 135-150.

ANDERSON, J.R. (1983), The Architecture of Cognition, Cambridge, MA: Harvard University Press

ANDERSON, E.T. y SIMESTER, D.I. (2004), "Long-run effects of promotion depth on new versus established customers: Three field studies", Marketing Science, Vol. 23, invierno, 4-20.

ANISIMOVA, T. y MAVONDO, F.T. (2010), "The performance implications of company-salesperson corporate brand misalignment”, European Journal of Marketing, Vol. 44 (6), 771-795.

ARGENTI, P.A. y DRUCKENMILLER, B. (2004), "Reputation and the corporate brand”, Corporate Reputation Review, Vol. 6 (4), 368-374.

BALACHANDER, S. y GHOSE, S. (2003), "Reciprocal spillover effects: A strategic belief of brand extensions”, Journal of Marketing, Vol. 67, enero, 412.

BALMER, J.M. y GRAY, E.R. (2003), “Corporate brands: what are they? What of them?, European Journal of Marketing, Vol. 37 (7/8), 972-997.

BARICH, H. y KOTLER, P. (1991), “A framework for image management”, MIT Sloan Management Review, Vol. 32, invierno, 94-104.

BARONE, M. y MINIARD, P.W. (2002), "Mood and brand extension judgments: Asymmetric effects for desirable versus undesirable brands", Journal of Consumer Psychology, Vol. 12 (4), 283-290.

BATRA, R. LEHMANN, D.R. y SINGH, D. (1993), "The brand personality component of brand goodwill: some antecedents and consequences", en AAKER, DAVID y BIEL, ALEXANDER (ed.), Brand Equity and Advertising, Lawrence Erlbaum Associates, Hillsdale, NJ.

BAUMGARTH, C. (2010), “'Living the Brand'brand orientation in the businessto-business sector”, European Journal of Marketing, Vol. 44 (5), 653-671. 
BELLMAN, L.M. (2005), "Entrepreneurs: Invent a new brand name or revive an old one?”, Business Horizons, Vol. 48, 215-222.

BIEHAL, G. y SHEININ, D.A. (1998), "Managing the brand in a corporate advertising environment: A decision-making framework for brand managers", Journal of Advertising, Vol. 27 (2), 99-110.

BOTTOMLEY, P.A. y DOYLE, J.R. (1996), "The formation of attitudes towards brand extensions: Testing and generalizing Aaker and Keller's model”, International Journal of Research in Marketing, Vol. 13 (4), 365-377.

BOTTOMLEY, P.A. y HOLDER, S. (2001), "Do we really know how consumers evaluate brand extensions: Empirical generalizations based on secondary analysis of eight studies”, Journal of Marketing Research, Vol. 38, noviembre, 494-500.

BRONIARCZYK, S.M. y GERSHOFF, A.D. (2003), "The reciprocal effects of brand equity and trivial attributes”, Journal of Marketing Research, Vol. 40, mayo, 161-175.

BRONIARCZYK, S.M. y ALBA, J.W. (1994), "The importance of the brand in brand extension”, Journal of Marketing Research, Vol. 31, mayo, 214-228.

BROWN, C.L. y CARPENTER, G.S. (2000), "Why is the trivial important? A reasons-based account for the effects of trivial attributes on choice”, Journal of Consumer Research, Vol. 26, marzo, 372-385.

BROWN, T.J. y DACIN, P. (1997), “The company and the product: Corporate associations and consumer product responses”, Journal of Marketing, Vol. 61, enero, 68-84.

BROWN, S., KOZINETS, R. y SHERRY, J.F. (2003), "Teaching old brands new tricks: Retro branding and the revival of brand meaning”, Journal of Marketing, Vol. 67 (3), julio, 19-33.

CAMPA, J.M. y GUILLÉN, M.F. (1999), “The Internalization of Exports: Firmand Location-Specific Factors in a Middle-Income Country", Management Science, 45 (11), 1463-1478.

CARBONARA, P. (2009), “The Rush to Grab Orphan Brands”, Business Week, 3 de agosto de 2009, 47.

CERVIÑO, JULIO (2002), Marcas Internacionales: Cómo crearlas y gestionarlas, editorial Pirámide, Madrid.

CERVIÑO, J. y RIVERA, J. (2007), "La globalización de las marcas españolas: liderazgo y notoriedad internacional”, Información Comercial Española, ${ }^{\circ}$ 839, 121-139.

CERVIÑO, J.; CUBILLO, J.M. y SÁNCHEZ, J (2005), "Made in Effect, Competitive Marketing Strategy and Brand Performance: An Empirical Analysis of Spanish Brands", Journal of The American Academy of Business, Vol.6 (2), pp. 237-243. 
CERVIÑO, J. y BAENA, V. (2009), "Cuantificación del renombre de la marca: una propuesta metodológica”, Investigación y Marketing - Aedemo, número 104, septiembre, 28-35.

CHEN, H. and HU, M. (2002), "An Analysis of Determinant of Entry Mode and its Impact on Performance”, International Business Review, 11, 193-210.

DE CHERNATONY, L., HALLIBURTON, C. y BERNATH, R. (1995), “ International branding: demand- or supply-driven opportunity? . International Marketing Review, 12(2), 9-22.

DE CHERNATONY, L., COTTOMA, S. y SEGAL-HORN, M. (2006), "Communication service brands' values internally and externally", The Service Industries Journal, Vol. 26 (8), 819-837.

DE SOUZA, G. (1997), "Royalty Methods for Intellectual Property", Business Economics, abril, vol. 32, número 2, pp. 46-52.

DESAI, K. y KELLER, K.L. (2002), "The effects of brand expansions and ingredient branding strategies on host brand extendibility", Journal of Marketing, Vol. 66, julio, 73-93.

DOONAN, J. y TIEN, J. (2002), "The best method for determining cost-sharing payments”, International Tax Review, Vol. 13 (9), octubre, 37-38.

DOWLING, G.R. (1994), Corporate Reputations, Kogan-Page, Londres, Reino Unido.

DUNCAN, T. (2002), IMC: Using Advertising and Promotion to Build Brands, McGraw-Hill, Nueva York.

DURÁN, JUAN JOSÉ et al. (2002), Las marcas renombradas españolas. Un activo estratégico para la internacionalización, Foro de Marcas Renombradas Españolas-ICEX, Madrid.

DURÁN, J.J. y ÚBEDA, F (2001), “The investment development path: a new empirical approach and some theoretical issues”, Transnacional Corporation, 10(2), 1-34.

DURÁN, J.J. y ÚBEDA, F. (2004), "La marca como factor determinante de la inversión directa española en el exterior”, Revista Española de Marketing, Vol. 7 (2), 25-55.

DURÁN, J.J. y ÚBEDA, F. (2005), The Investment Development Path of Newly Developed Countries”, International Journal of the Economics of Business, 12(1), 123-137.

EDELL, J.A. y KELLER, K.L. (1989), "The information processing of coordinated media campaigns”, Journal of Marketing Research, Vol. 26, mayo, 149-163.

ERDEM, T. y SWAIT, J. (2004), "Brand credibility, brand consideration, and choice”, Journal of Consumer Research, Vol. 31, junio, 191-198.

FARQUHAR, P.H., HAN, J.Y., HERR, P.M. y IJIRIi, Y. (1992), "Strategies for leveraging master brands”, Marketing Research, Vol. 4, septiembre, 32-43. 
FOLKES, V. y MATTA, S. (2004), "The effect of package shape on consumers' judgments of product volume”, Journal of Consumer Research, Vol. 31, septiembre, 390-402.

FOURNIER, S.M. (1998), "Consumers and their brands: Developing relationship theory in consumer research”, Journal of Consumer Research, Vol. 24, marzo, 343-373.

FOURNIER, S.M. y YAO, J.L. (1997), "reviving brand loyalty: A reconceptualization within the framework of consumer-brand relationships", International Journal of Research in Marketing, Vol. 14, 451-472.

FRAEDRICH, J., BATEMAN, C. (1996), "Transfer pricing by multinational marketers:Risky business”, Business Horizons, Vol. 39 (1), enero-febrero, 1724.

GELDER, S.V. (2005), "The new imperatives for global branding: Strategy, creativity and leadership”, Journal of Brand Management, Vol. 12 (5), Junio, 395-404.

GEYLANI, T., INMAN, J. y HOFSTEDE, F.T. (2008), "Image reinforcement or impairment: The effects of Co-Branding on attribute uncertainty", Marketing Science, Vol. 27 (4), julio-agosto, 730-744.

GILSON, J. y GILSON-LALONDE, A. (2008), "The Zombie Trademark: A Windfall and A Pitfall”, The Trademark Reporter, Vol. 98 (6), noviembrediciembre, 1379-1424.

GLAZER, R. (1991), "Marketing in an information-intensive environment: Strategic implications of knowledge as an asset”, Journal of Marketing, 55(4), $1-20$.

GRAEFF, T.R. (1997), "Consumption situations and the effects of brand image on consumers' brand evaluations”, Psychology and Marketing, Vol. 14 (1), 4970.

GRUCA, T., y REGO, L. (2005), "Customer Satisfaction, Cash Flow, and Shareholder Value”, Journal of Marketing, 69(3), 115-130.

GUPTA, S. LEHMANN, D.R y STUART, J.A. (2004), "Valuing customers", Journal of Marketing Research, Vol. 41, febrero, 7-18.

GÜRHAN-CANLI, Z. y BATRA, R. (2004), "When corporate image affects product evaluations: The moderating role of perceived risk", Journal of Marketing Research, Vol. 41, mayo, 197-205.

GÜRHAN-CANLI, Z. y MAHESWARAN, D. (1998), "The Effects of Extensions on Brand Name Dilution and Enhancement”, Journal of Marketing Research, Vol. 35 (4), noviembre, 464-473.

HENDERSON, P.W. y COTE, J.A. (1998), "Guidelines for selecting or modifying logos”, Journal of Marketing, Vol. 62 (2), 14-30.

HENDERSON, P.W., GEISE, J.L. y COTE, J.A. (2004), “Impression management using typeface design”, Journal of Marketing, Vol. 68 (4), 60-72. 
HERR, P.M., FARQUAR, P.H. y FAZIO, R.H. (1996), “Impact on Dominance and Relatedness on Brand Extensions”, Journal of Consumer Psychology, Vol. 5 (2), 135-159.

HILL, H. y KIM CH. (1990), "An Eclectic Theory of the Choice of International Entry Mode”, Strategic Management Journal, 11 (2), 117-128

HOEFFLER, S. y KELLER, K.L. (2003), "The marketing advantages of strong brands”, Journal of Brand Management, Vol. 10 (6), 421-445.

IGLESIAS, O., SINGH, F. y CASABAYÓ, M. (2011), "Key changes and challenges for brands in an uncertain environment", Journal of Product and Brand Management, Vol. 20 (6), 436-439.

INTERBRAND (2011), The Best Global Brands - The Most Valuable Brands, 2011.

ITAMI, H y ROEHL, T.W. (1987), Mobilizing invisible assets, Harvard University Press, Cambridge, M.A.

JACOBY, J. (2008), "Considering the Who, What, When, Where and How of Measuring Dilution”, Santa Clara Computer \& High Tech Law Journal, 24(3), 101-139.

JANISZEWSKI, C., VAN OSSELAER, S.M.J. (2000), “A connectionist model of brand-quality associations”, Journal of Marketing Research, Vol. 37, agosto, 331-350.

KAPFERER, J.N. (2005), The New Strategic Brand Management, Kogan-Page, Londres, R.U.

KARDER, F.R. y GURUMURTHY, K. (1992), "Order-to-Entry Effects on Consumer Memory and Judgment: An Information Integration Perspective”, Journal of Marketing Research, Vol 39, agosto, 343-357.

KRASNIKOV, A., MISHRA, S., y OROZCO, D. (2009), "Evaluating the Financial Impact of Branding Using Trademarks: A Framework and Empirical Evidence”, Journal of Marketing, 73(6), 154-166.

KELLER, K.L. (1993), "Conceptualizing, measuring and managing customerbased brand equity", Journal of Marketing, Vol. 57, agosto, pp. 1-22.

KELLER, KEVIN LANE (1998), Strategic Brand Management, Englewood Cliffs, Prentice- Hall

KELLER, K.L. (2001), "Building customer-based brand equity: A blueprint for creating strong brands", Marketing Management, Vol. 10, julio-agosto, 15-19.

KELLER, K.L. (2002), Branding and brand equity, en BART WEITZ y ROBIN WENSLEY (ed.), Handbook of Marketing, Sage Publications, Londres, Reino Unido.

KELLER, KEVIN LANE (2003), Strategic Brand Management: Building, Measuring, and Managing Brand Equity, $2^{\mathrm{a}}$ edición, Prentice Hall, Upper Saddle River, NJ.

KELLER, K.L. y AAKER, D.A. (1992), "The effects of sequential introduction of brand extensions”, Journal of Marketing Research, Vol. 29, mayo, 35-50. 
KELLER, K.L. y LEHMANN, D.R (2003), “The brand value chain: Optimizing strategic and financial brand performance", Marketing Management, mayo/junio, 26-31.

KELLER, K. y LEHMANN, D. R. (2006), "Brands and Branding: Research Findings and Future Priorities”, Marketing Science, Vol. 23 (6), 740-759.

KELZ, A. y BLOCK, B. (1993), "Global Branding: Why and How", Industrial Management + Data, Vol. 93 (4), 11-17.

KLINK, R.R. (2000), "Creating brand names with meaning: The use of sound symbolism”, Marketing Letters, Vol. 11 (1), 5-20.

KLINK, R.R. y SMITH, D.C. (2001), "Threats to external validity of brand extensions research”, Journal of Marketing Research, Vol. 38, agosto, 326335.

KOHLI, C. y LABAHN, D.W. (1997), "Creating effective brand names: A study of the naming process”, Journal of Advertising Research, Vol. 37, enero-febrero, 67-75.

KOTLER, PHILIP. y KELLER, KEVIN LANE (2006), Marketing Management, $12^{a}$ edición, Prentice Hall, Upper Saddle River, NJ.

KUMAR, N. (2003), “Kill a brand, keep a customer”, Harvard Business Review, 81, diciembre, 86-96.

LACZNIAK, R.N., DECARLO, T.E. y RAMASWAMI, S. (2001), "Consumers' responses to negative Word-of-mouth communication: An attribution theory perspective”, Journal of Consumer Psychology, Vol. 11 (1), 57-73.

LEEK, S. y CHRISTODOULIDER, G. (2011), "A literature review and future agenda for B2B branding: Challenges of branding in a B2B context", Industrial Marketing Management, Vol. 40, 830-837.

LEVITT, T. (1983), "The globalization of markets", Harvard Business Review, Vol. 61, mayo-junio, 92-102.

LEONG, S.M. (1997), "Dominance and dilution: the effects of extending master brands", The Journal of Consumer Marketing, 14 (5), 380-390

LILIEN, G.L. y YOON, E. (1990), "The Timing of Competitive Market Entry: An Exploratory Study of New Industrial Products”, Management Science, 28, mayo, 568-585.

LIPPMAN, S. y RUMLETS, R.S. (1982), "Uncertain imitability: An analysis of inter-firm differences in efficiency under competition”, Bell Journal of Economics, 13, 418-438.

LOKEN, B. y ROEDDER J. D. (1993), "Diluting brand beliefs: When do brand extensions have a negative impact?” Journal of Marketing, Vol. 57, Julio, pp. 71-84. 
LUOSTARIANEN, R. y GABRIELSON, M (2004), "Finnish Perspective of International Entrepreneurship”, en DANA, L. P. (coord.), Handbook of Research on International Entrepreneurship, Cheltenham, Edward Elgar.

LUO, X. (2009), "Quantifying the Long-Term Impact of Negative Word of Mouth on Cash Flows and Stock Prices”, Marketing Science, 28(1), 148-165.

LYNCH, J. y DE CHERNATONY, L. (2007), "Winning hearts and minds: Business to business branding and the role of the salesperson", Journal of Marketing Management, vol. 23 (1), 123-135.

MADHOK, A. (1998), "The Nature of Multinational Firm Boundaries: Transaction Cost, Firm Capabilities and Foreign Market Entry Mode”, International Business Review, 7, 259-290.

MAOZ, E. y TYBOUT, A.M. (2002), “The moderating role of involvement and differentiation in the evaluation of brand extensions", Journal of Consumer Psychology, Vol. 12 (2), 119-131.

MARTÍN, O. y CERVIÑO, J. (2011), “Towards an integrative framework of brand country of origin recognition determinants: A cross-classified hierarchical model”, International Marketing Review, Vol. 28 (6), 530-558.

MCALEXANDER, J.H., SCHOUTEN, J.W. y KOENIG, H.F. (2002), "Building brand community", Journal of Marketing, Vol. 66, enero, 38-54.

MILBERG, S.J., PARK, C.W. y MCCARTHY, M.S. (1997), "Managing negative feedback effects associated with brand extensions: The impact of alternative branding strategies”, Journal of Consumer Psychology, Vol. 6 (2), 119-140.

MILLWARD BROWN (2011), BrandZ - Optimor - Top 100 Most Valuable Global Brands 2010.

MIZIK, N., y JACOBSON, R. (2008), "The Financial Value Impact of Perceptual Brand Attributes”, Journal of Marketing Research, 45(1), 15-32.

MOORE, E.S., WILKIE, W.L. y LUTZ, R.J. (2002), "Passing the torch: Intergenerational influences as a source of brand equity", Journal of Marketing, Vol. 66, abril, 17-37.

MORRIN, M. (1999), "The Impact of Brand Extensions on Parent Brand Memory Structures and Retrieval Processes”, Journal of Marketing Research, Vol. 46, (4), 517-525.

MORRIN, M. y JACOBY, J. (2000), “Trademark Dilution: Empirical Measures for an Elusive Concept”, Journal of Public Policy \& Marketing, Vol. 19 (2), 265276.

MORRIN, M., LEE, J., y ALLENBY, G. (2006), "Determinants of Trademark Dilution”, Journal of Consumer Research, 33(2), 248-257.

MUNIZ, A.M. y O'GUINN, T.C. (2000), "Brand Community", Journal of Consumer Research, Vol. 27, marzo, 412-432.

NAIK, P.A., RAMAN, K. y WINER, R.S. (2005), "Planning marketing-mix strategies in the presence of interaction effects”, Marketing Science, Vol. 24 (1), 25-34. 
ONKVISIT, S. y SHAW, J.J. (1989), “The International Dimension of Branding: Strategic Considerations and Decisions”, International Marketing Review, 6(3), 22-35.

OHNEMUS, L. (2009), “B2B branding: a financial burden for shareholders?”, Business Horizons, Vol. 52, 159-166.

PAN, Y. y SCHMITT, B. (1996), "Language and brand attitudes: Impact of script and sound matching in Chinese and English", Journal of Consumer Psychology, Vol. 5 (3), 263-277.

PARK, C.S. y SRINIVASAN, V. (1994), "A survey-based method for measuring and understanding brand equity and its extendability”, Journal of Marketing Research, Vol. 31, mayo, 271-288.

PARK, C.W., JAWORSKI, B.J. y MACINNIS, D.J. (1986), "Strategic Brand Concept-Image Management”, Journal of Marketing, Vol. 50, octubre, 135145.

PETERSON, R.A.; SMITH, K.H; y ZERRILLO, P.C. (1999), "Trademark Dilution and the Practice of Marketing”, Academy of Marketing Science Journal, Vol. 27 (2), primavera, 255-268.

PETERSON, R.A., y JEONG, J. (2010), “Exploring the impact of advertising and $\mathrm{R} \& \mathrm{D}$ expenditures on corporate brand value and firm-level financial performance”, Journal of the Academy of Marketing Science, 38(6), 677-690.

PLÁ, J. (1999), "Filiales de entrada en los mercados internacionales. Factores determinantes”, Revista de Economía Aplicada, 20, 29-51.

PULLIG, C. SiMMONS, C.J. y NETEMEYER, R.G. (2006), "Brand Dilution: When do new brands hurt existing brands?”, Journal of Marketing, Vol. 70, abril, 52-66.

PUTSIS, W.P. y BAYUS, B.L. (2001), “An empirical analysis of firms' product line decisions”, Journal of Marketing Research, Vol. 38, febrero, 110-118.

RANGASWAMY, A. BURKE, R.R. y OLIVA, T.A. (1993), "Brand equity and the extendibility of brand names", International Journal of Research in Marketing, Vol. 10 (3), 61-75.

RAO, A.R., QU, L. y RUEKERT, R.W. (1999), "Signaling unobservable product quality through a brand ally", Journal of Marketing Research, Vol. 36, mayo, 258-268.

RAO, R., y BHARADWAJ, N. (2008), "Marketing Initiatives, Expected Cash Flows, and Shareholders' Wealth”, Journal of Marketing, 72(1), 16-26.

RATTRAY, A. (2002), 'Measure for measure', Financial Times, 9 de julio.

REDDY, S.K.; HOLAK, S.L. y BHAT, S. (1994), "To extend or not to extend: Success determinant of the line extensions", Journal of Marketing Research, Vol. 31, mayo, 243-262. 
RIALP, A. (1999), "Los determinantes de la internacionalización del canal de distribución internacional: Un análisis comparativo”, Cuadernos de Economía y Dirección de la Empresa, 3, 141-166.

ROEDDER, J.D.; LOKEN, B. y JOINER, C. (1998), "The negative impact of extensions: Can flagship brands products be diluted?” Journal of Marketing, Vol. 62, enero, 19-32.

ROBERTS, J. y CAYLA, J. (2009), “Global branding”, en KOTABE, M. y HELSEN, K. (Ed.), The Sage Handbook of Inter-national Marketing, Sage, Los Angeles, CA.

ROBINSON, W.T. (1998), "Sources of Market Pioneer Advantages; The case of industrial goods industries”, Journal of Marketing Research, 25, febrero, 8794.

SALINAS, GABRIELA. (2007a), Valoración de Marcas. Revisión de enfoques, metodologías y proveedores, Editorial Deusto-Instituto de Análisis de Intangibles, Madrid.

SALINAS, G. (2007b), "Buscando una medida confiable de valor de marca. De la jungla al jardín del edén”, Marketing y Ventas, 228, octubre, 34-38.

SAMIEE, S. y ROTH, K. (1992), "The influence of global marketing standardization on performance”, Journal of Marketing, Vol. 56, abril, 1-17.

SASHI, C.M. y KARUPPUR, D.P. (2002), "Franchisisng in global markets: towards a conceptual framework “, International Business Review, Vol. 19, 499-524

SCHMITT, B.H. (1999), Experiential Marketing: How to get customer s to Sense, Feel, Think, Act and Relate to your company and brand, Free Press; Nueva York.

SCHMITT, B.H. (2003), Experience Management: A Revolutionary Approach to Connecting with Your Customers, John Wiley \& Sons, Hoboken, NJ.

SCHOUTEN, J.W. y MCALEXANDER, J.H. (1995), "Subcultures of consumption: An ethnography of the new bikers", Journal of Consumer Research, Vol. 22, junio, 43-61.

SIMON, I. (2006), "The Actual Dilution Requirement of the United States, United Kingdom and European Union: A Comparative Analysis”, Boston University Journal of Science \& Technology Law, Vol. 12, 271-289.

SIMONIN, B.L. y RUTH, J.A. (1998), "Is a company known by the company it keeps? Assesing the spillover effects of brand alliances on consumer brand attitudes”, Journal of Marketing Research, Vol. 35 (2), 30-42.

SIMONSON, A. (1995), "How and When Do Trademarks Dilute: A Behavioral Framework to Judge 'Likelihood' of Dilution”, The Trademark Reporter, Vol. 83 (2), 149-174.

SMITH, D.C. y PARK, C.W. (1992), "The effects of brand extensions on market share and advertising efficiency”, Journal of Marketing Research, Vol. 29, agosto, 296-313. 
SMITH, R.E. y VOGT, C.A. (1995), "The effects of integrating advertising and negative word of mouth communications on message processing and response”, Journal of Consumer Psychology, Vol. 4, 2, 133-152.

SORESCU, A., SHANKAR, V., y KUSHWAHA, T. (2007), "New Product Preannouncements and Shareholder Value: Don't Make Promises You Can't Keep”, Journal of Marketing Research, 44(3), 468-489.

SPYROPOULOU, S., SKARMEAS, D. y KATSIKEAS, C. (2011), “An examination of branding advantage in export ventures", European Journal of Marketing, Vol. 45 (6), 910-935.

SRIVASTAVA, R.K., SHERVANI, T.A. y FAHEY, L. (1998), "Market-based assets and shareholder value: A framework for analysis", Journal of Marketing, Vol. 62 (1), 2-18.

SRIVASTAVA, R.K., FAHEY, L. y CHRISTENSEN, H. (2001), "The ResourceBased View and Marketing: The Role of Market-Based Assets in Gaining Competitive Advantage”, Journal of Management, 27, 777-802.

SRINIVASAN, S., PAUWELS, K., SILVA-RISSO, J., y HANSSENS, D. (2009), «Product Innovations, Advertising, and Stock Returns”, Journal of Marketing, 73(1), 24-43.

STEENKAMP, J.B., BATRA, R. y ALDEN, D. (2003), "How perceived brand globalness creates brand value”, Journal of International Business Studies, Vol. 34, 53-65.

SUTHERLAND, M. y SYLVESTER, A.K. (2000), Advertising and the mind of the consumer: what works, what doesn't, and why, Allen \& Unwin ( $2^{\mathrm{a}}$ edición).

TOWNSEND, J.D, YENIYURT, S. y TALAY, M.B. (2009), "Getting to global: An evolutionary perspective of brand expansion in international markets", Journal of International Business Studies, Vol. 40, 539-558.

URDE, M. (1999), "Brand orientation: a mindset for building brand into strategic resources”, Journal of Marketing Management, Vol. 15 (13), 117-133.

VÖLCKNER, F. y SATTLER, H. (2006), "Drivers of Brand Extension Success", Journal of Marketing, Vol. 70, abril, 18-34.

WILLIAMSON, OLIVER. (1975), Market and Hierarchies: Analysis and Antitrust Implications: a Study of Economics of Internal Organizations, Nueva York, Free Press

WHITELOCK, J. y FASTOSO, F. (2007), "Understanding international branding: defining the domain and reviewing the literature", International Marketing Review, Vol. 24 (3), 252-270. 


\begin{tabular}{|c|c|c|}
\hline \multicolumn{3}{|c|}{$\begin{array}{l}\text { Anexo I } \\
\text { Principales Líneas de Investigación en el Área de Marcas }\end{array}$} \\
\hline Pri & cipales Líneas de investigación & Principales autores y trabajos \\
\hline \multicolumn{3}{|c|}{ El Posicionamiento de la marca } \\
\hline & $\begin{array}{l}\text { Atributos intangibles: asociaciones de la marca, historia, } \\
\text { experiencias. }\end{array}$ & $\begin{array}{l}\text { Park et. Al. (1986), Keller (2001) Kotler y Keller } \\
\text { (2006) }\end{array}$ \\
\hline & $\begin{array}{l}\text { Personalidad de la marca: principales atributos de la } \\
\text { personalidad de las marcas de productos/servicios, } \\
\text { corporativas y de ciudad/país. Desarrollo de escalas de } \\
\text { personalidad de marca. }\end{array}$ & $\begin{array}{l}\text { Aaker (1997), Aaker (1999), Aaker et al. (2001), } \\
\text { Graeff (1997), }\end{array}$ \\
\hline & $\begin{array}{l}\text { Relaciones de la marca con sus públicos objetivos: } \\
\text { dimensiones de la relación, tipologías y escalas de medida. }\end{array}$ & $\begin{array}{l}\text { Fournier y Yao (1997), Fournier (1998), Aaker et } \\
\text { al. (2004), Aggarwal (2004) }\end{array}$ \\
\hline & $\begin{array}{l}\text { Marketing experimental y su aplicación a la marca (Brand } \\
\text { experience): el modelo (CEM) - Customer Experience } \\
\text { Management) y su aplicación a las marcas. }\end{array}$ & Schmitt $(1999,2003)$ \\
\hline & $\begin{array}{l}\text { Imagen y Reputación Corporativa: Conceptualización, } \\
\text { antecedentes y consecuencias; marcas corporativas vs } \\
\text { marcas de productos; identidad social corporativa. }\end{array}$ & $\begin{array}{l}\text { Barich y Koktler (1991), Keller y Aaker (1992), } \\
\text { Dowling (1994), Brown y Dacin (1997), Biehal y } \\
\text { Sheinin (1998), Gürhan-Canli y Batra (2004), } \\
\text { Argenti y Druckenmiller (2004), Erdem y Swait } \\
\text { (2004) }\end{array}$ \\
\hline \multicolumn{3}{|c|}{ Integración de la gestión del Marketing y las Marcas } \\
\hline & $\begin{array}{l}\text { Integración de los elementos de la marca: concepto de } \\
\text { identidad de marca, selección y gestión de nombre de } \\
\text { marca y logos, elementos visuales de la marca, decisiones } \\
\text { de packaging, internacionalización de los elementos de la } \\
\text { marca. }\end{array}$ & $\begin{array}{l}\text { Henderson y Cote (1998), Kohli y LaBahn (1997), } \\
\text { Klink (2000), Garber et al. (2000), Zhang y } \\
\text { Schmitt (2001), Tavassoli y Han (2002), Keller } \\
\text { (2003), Wansink y van Ittersum (2003), Henderson } \\
\text { et al. (2004), Yorkston y Menon (2004), Folkes y } \\
\text { Matta (2004), Kapferer (2005). }\end{array}$ \\
\hline & $\begin{array}{l}\text { Integración de las decisiones de comunicación y } \\
\text { distribución: efectos a corto, medio y largo de la publicidad } \\
\text { en el valor de la marca }\end{array}$ & $\begin{array}{l}\text { Edell y Keller (1989), Ailawadi et al. (2001), } \\
\text { Duncan (2002), Naik y Raman (2003), Anderson y } \\
\text { Simester (2004). }\end{array}$ \\
\hline & $\begin{array}{l}\text { Gestión de la interacción entre variables de control y } \\
\text { eventos externos: las comunidades de la marca, formas } \\
\text { alternativas de creación de valor de marca, rituales, } \\
\text { subculturas de consumo, el boca-oreja. }\end{array}$ & $\begin{array}{l}\text { Smith y Vogt (1995), Schouten y McAlexander } \\
\text { (1995), Muniz y O'Guinn (2000), Laczniak et al. } \\
\text { (2001), McAlexander et al. (2002), Moore et al. } \\
\text { (2002) }\end{array}$ \\
\hline \multicolumn{3}{|c|}{ Cuantificación del valor de marca (capital de marca) } \\
\hline & $\begin{array}{l}\text { Medición y valoración del capital (valor) de marca: valor } \\
\text { de la marca para el consumidor; valor de la marca en el } \\
\text { mercado en términos de eficiencia competitiva, } \\
\text { crecimiento, barreras de entrada y ventajas monopolísticas; } \\
\text { valor financiero de la marca en transacciones financieras y } \\
\text { contratos de licencias. Metodologías de valoración } \\
\text { financiera. }\end{array}$ & $\begin{array}{l}\text { Keller (1993), Simon y Sullivan (1993), Park y } \\
\text { Srinivasan (1994), Aaker y Jacobson (1994), } \\
\text { Feldwick (1996), Srivastava et al. (1998), Ambler } \\
\text { y Barwise (1998), Brown y Carpenter (2000), } \\
\text { Broniarczyk y Gershoff (2003), Hoeffler y Keller } \\
\text { (2003), Keller y Lehmann (2003), Ambler (2004). }\end{array}$ \\
\hline & $\begin{array}{l}\text { Valor del consumidor y valor de marca (Customer-level } \\
\text { Brand equity): la notoriedad de la marca como base del } \\
\text { valor de la marca, las estructuras del conocimiento de las } \\
\text { marcas, modelos académicos y comerciales, el valor del } \\
\text { consumidor y valor corporativo (stock market). }\end{array}$ & $\begin{array}{l}\text { Agrawal y Rao (1996), Aaker (1996), Keller } \\
\text { (2003), Zaltman (2003), Villas-Boas (2004), Gupta } \\
\text { et al. (2004). Modelos comerciales: Young \& } \\
\text { Rubicam's Brand Asset Valuator (BAV), } \\
\text { Interbrand, WPP's Brand Z, Research } \\
\text { International's Equity Engine. }\end{array}$ \\
\hline \multicolumn{3}{|c|}{ Estrategias de crecimiento y apalancamiento de marcas. } \\
\hline & $\begin{array}{l}\text { Extensión de marcas. Desarrollo de nuevos productos, } \\
\text { ampliación de líneas y extensión de marca a otras } \\
\text { categorías. Problemas de dilución con las extensiones de } \\
\text { marca. }\end{array}$ & $\begin{array}{l}\text { Aaker y Keller (1990), Smith y Park (1992), Batra } \\
\text { et al. (1993), Rangaswamy et al. (1993), Reddy et } \\
\text { al. (1994), Bottomley y Doyle (1996), Milberg et } \\
\text { al. (1997), Ahluwalia y Gürhan-Cali (2000), Klink } \\
\text { y Smith (2001), Bottomley y Holden (2001), } \\
\text { Barone y Miniard (2002), Maoz y Tybout (2002), } \\
\text { Zhang y Sood (2002), Osselaer y Alba (2003), }\end{array}$ \\
\hline
\end{tabular}




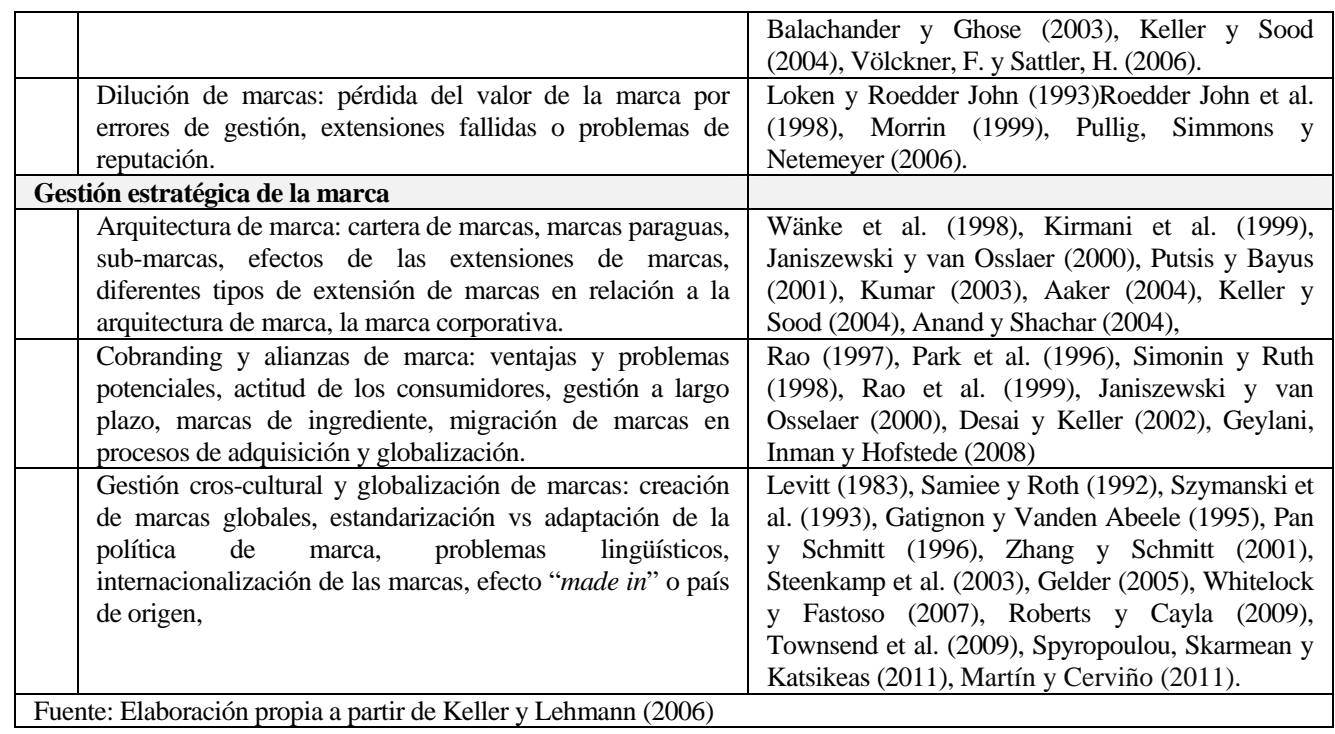

